\title{
Assessing the performance of the FAO AquaCrop model to estimate maize yields and water use under full and deficit irrigation with focus on model parameterization
}

\author{
P. Paredes, J.P. de Melo-Abreu, I. Alves, L.S. Pereira* \\ CEER-Biosystems Engineering, Instituto Superior de Agronomia, Universidade de Lisboa, Tapada da Ajuda, 1349-017 Lisboa, Portugal
}

\section{A R T I C L E I N F O}

\section{Article history:}

Received 5 March 2014

Accepted 1 June 2014

Available online 26 June 2014

\section{Keywords:}

Crop growth model

Yield-water relations

Canopy cover

Biomass and yield predictions

SIMDualKc model

Dual crop coefficients

\begin{abstract}
A B S T R A C T
Several maize field experiments, including deficit and full irrigation, were performed in Ribatejo region, Portugal and were used to assess water stress impacts on yields using the AquaCrop model. The model was assessed after its parameterization using field observations relative to leaf area index (LAI), crop evapotranspiration, soil water content, biomass and final yield data and also using default parameters. LAI data were used to calibrate the canopy cover (CC) curve. Results showed that when the CC curve is properly calibrated, with root mean square errors (RMSE) smaller than $7.4 \%$, model simulations, namely relative to crop evapotranspiration and its partition, show an improved accuracy. The model performance relative to soil water balance simulation revealed a bias in estimation but low estimation errors, with RMSE $<13 \%$ of the total available soil water. However the model tends to overestimate transpiration and underestimate soil evaporation. A good model performance was obtained relative to biomass and yield predictions, with RMSE lower than $11 \%$ and $9 \%$ of the average observed biomass and yield, respectively. Overall results show adequacy of AquaCrop for estimating maize biomass and yield under deficit irrigation conditions, mainly when an appropriate parameterization is adopted. The model showed less good performance when using the default parameters but errors are likely acceptable when field data are not available.
\end{abstract}

(c) 2014 Elsevier B.V. All rights reserved.

\section{Introduction}

Selecting the best irrigation schedule is required for improved use of the available water and for achieving the best yields. That selection implies appropriate prediction of the yield response to water, which is in the origin of numerous studies on water-yield responses to a variety of water stresses imposed throughout the crop season.

Several studies have been performed on maize showing the impacts of water deficits by reducing crop growth and canopy development (NeSmith and Ritchie, 1992), changing morphological characteristics of the plants (Traore et al., 2000; Stone et al., 2001a,b; Çakir, 2004), reducing the number and weight of kernels (Weerathaworn et al., 1992; Karam et al., 2003), and thus reducing yields (Stewart et al., 1977; Doorenbos and Kassam, 1979).

In the extensive work by Stewart et al. (1977) results showed different maize yield responses when water stress was imposed

\footnotetext{
* Corresponding author. Tel.: +351213653480; +351213653339.

E-mail addresses: lspereira@isa.ulisboa.pt, lspereira@isa.utl.pt, luis.santospereira@gmail.com (L.S. Pereira).
}

at different growth stages, with higher impacts when water stress occurred during the flowering period. Other sensitive periods are those of grain filling and the end of the vegetative stage. The same conclusion was reported by Denmead and Shaw (1960) and Westgate and Grant (1989). For maize, lower yield losses due to mild stress during flowering are to be expected when the crop has already been subject to stress during the vegetative stage (Stewart et al., 1977). Alves et al. (1991) also noticed this conditioning behaviour when reporting results of an extensive field work on determining impacts of water stress on maize.

Simulation models may be helpful for assessing the impacts of water stress in crop yield. There are several studies using mechanistic models that allow determining biomass and yields and that may also be used for evaluating crop and irrigation management practices. Examples of applications of these models to maize include the use of CERES-Maize (Panda et al., 2004; DeJonge et al., 2012), CropSyst (Stöckle et al., 2003), EPIC (Cavero et al., 2000; Ko et al., 2009) and STICS (Katerji et al., 2010). A combination of the water balance model SIMDualKc (Rosa et al., 2012) with the phasic Stewart's water yield model (Stewart et al., 1977) was recently tested when using maize transpiration as driving variable (Paredes et al., 2014a). The crop growth model recently proposed by FAO, AquaCrop (Steduto 


\begin{tabular}{|c|c|}
\hline AAE & average absolute error (same units as observations) \\
\hline ASW & available soil water $(\mathrm{mm})$ \\
\hline$B$ & above ground dry biomass $\left(\mathrm{tha}^{-1}\right)$ \\
\hline$b$ & regression coefficient (non-dimensional) \\
\hline BWP* & $\begin{array}{l}\text { Biomass (water) productivity adjusted for } \mathrm{ET}_{\mathrm{o}} \text { and } \\
\mathrm{CO}_{2}\left(\mathrm{~g} \mathrm{~m}^{-2}\right)\end{array}$ \\
\hline $\mathrm{CC}^{*}$ & $\begin{array}{l}\text { actual crop canopy cover adjusted for micro- } \\
\text { advective effects }(\%)\end{array}$ \\
\hline $\mathrm{CC}_{\mathrm{o}}$ & canopy cover at $90 \%$ emergence ( $\mathrm{cm}^{2}$ per plant) \\
\hline $\mathrm{CC}_{\mathrm{X}}$ & maximum canopy cover (\%) \\
\hline CDC & canopy decline coefficient (\% GDD ${ }^{-1}$ ) \\
\hline CGC & canopy growth coefficient $\left(\% \mathrm{GDD}^{-1}\right)$ \\
\hline $\mathrm{CN}$ & curve number (non-dimensional) \\
\hline$D$ & irrigation depths $(\mathrm{mm})$ \\
\hline $\mathrm{EF}$ & modelling efficiency (non-dimensional) \\
\hline$E_{S}$ & soil evaporation (mm) \\
\hline $\mathrm{ET}_{\mathrm{C}}$ & $\begin{array}{l}\text { standard (non-stressed) crop evapotranspiration } \\
(\mathrm{mm})\end{array}$ \\
\hline $\mathrm{ET}_{\mathrm{C} \text { adj }}$ & adjusted or actual crop evapotranspiration (mm) \\
\hline $\mathrm{ET}_{0}$ & reference evapotranspiration (mm) \\
\hline$f_{c}$ & $\begin{array}{l}\text { fraction of soil cover by vegetation (non- } \\
\text { dimensional) }\end{array}$ \\
\hline$f_{\mathrm{HI}}$ & $\begin{array}{l}\text { adjustment factor integrating five water stress fac- } \\
\text { tors (non-dimensional) }\end{array}$ \\
\hline $\mathrm{HI}$ & harvest index (\%) \\
\hline $\mathrm{HI}_{\mathrm{o}}$ & reference harvest index (\%) \\
\hline$K_{\mathrm{cb}}$ & basal crop coefficient (non-dimensional) \\
\hline$K_{\mathrm{cb} \text { adj }}$ & adjusted basal crop coefficient (non-dimensional) \\
\hline$K_{\mathrm{cb} \text { mid }}$ & $\begin{array}{l}\text { basal crop coefficient for the mid season (non- } \\
\text { dimensional) }\end{array}$ \\
\hline$K_{c \operatorname{Tr}, x}$ & $\begin{array}{l}\text { maximum standard crop transpiration coefficient } \\
\text { (non-dimensional) }\end{array}$ \\
\hline$K_{\mathrm{ex}}$ & $\begin{array}{l}\text { maximum soil evaporation coefficient (non- } \\
\text { dimensional) }\end{array}$ \\
\hline$K_{r}$ & $\begin{array}{l}\text { evaporation reduction coefficient (non- } \\
\text { dimensional) }\end{array}$ \\
\hline$K_{s}$ & water stress coefficient (non-dimensional) \\
\hline$K_{\text {sat }}$ & saturated hydraulic conductivity $\left(\mathrm{cm} \mathrm{d}^{-1}\right)$ \\
\hline LAI & leaf area index $\left(\mathrm{cm}^{2} \mathrm{~cm}^{-2}\right)$ \\
\hline$P_{e}$ & precipitation (mm) \\
\hline$R^{2}$ & determination coefficient (non-dimensional) \\
\hline REW & readily evaporable soil water $(\mathrm{mm})$ \\
\hline RMSE & root mean square error (same units as observations) \\
\hline & actual (or adjusted) transpiration ( $\mathrm{mm}$ ) \\
\hline TAW & total available soil water $(\mathrm{mm})$ \\
\hline$T_{c}$ & crop transpiration (mm) \\
\hline TEW & total evaporable water (mm) \\
\hline$Y$ & actual yield ( $\mathrm{tha}^{-1}$ ) \\
\hline$Z_{r}$ & root depth $(\mathrm{m})$ \\
\hline$\theta_{\mathrm{FC}}$ & volumetric water content at field capacity $\left(\mathrm{m}^{3} \mathrm{~m}^{-3}\right)$ \\
\hline$\theta_{\text {sat }}$ & volumetric water content at saturation $\left(\mathrm{m}^{3} \mathrm{~m}^{-3}\right)$ \\
\hline$\theta_{\mathrm{WP}}$ & volumetric water content at wilting point $\left(\mathrm{m}^{3} \mathrm{~m}^{-3}\right)$ \\
\hline
\end{tabular}

et al., 2012), was selected for the present study because of its novelty and yet already wide application not only to maize (Hsiao et al., 2009; Heng et al., 2009; Katerji et al., 2013), but also cotton (Farahani et al., 2009), barley (Araya et al., 2010), and wheat (Andarzian et al., 2011).

Despite the existence of a large number of publications on applications of AquaCrop, information relative to parameterization, calibration and validation provided by the model authors (Hsiao et al., 2009) and the reference manual (Raes et al., 2012), as well as by other authors, is insufficient. Users may have a hard task when trying to correctly use the model, which becomes even harder when crops have not been previously parameterized by FAO (Raes et al., 2012). In addition, available publications often do not assess the performance of the model in simulating the available soil water, or in describing the canopy cover curve. There are a few studies that discuss model limitations (Farahani et al., 2009; Andarzian et al., 2011; Katerji et al., 2013; Paredes et al., 2014b,c). Difficulties were referred by Heng et al. (2009) and Katerji et al. (2013) relative to the AquaCrop application to maize when high water stress is considered. Farahani et al. (2009) referred to limitations in estimating the water balance components in applications to cotton.

Considering that some of the studies referred above have shown the need for a better parameterization of the model, particularly for conditions of water stress, the present study aims at testing AquaCrop for biomass and yield predictions of maize under various deficit irrigation levels and timings, and to assess the performance of the model using different parameterization approaches, including the adoption of the default parameters provided by Raes et al. (2012). In addition, the parameterization is analyzed relative to the canopy cover curve, the simulation of the available soil water, and the prediction of biomass and harvestable yield.

\section{Material and methods}

\subsection{Case studies}

\subsubsection{Real farming maize production}

Observations were performed in farmer's fields at "Quinta da Lagoalva de Cima”, located in Alpiarça, central Portugal. This farm has a total of 200 ha cropped with maize. Daily weather data were observed in a meteorological station located nearby $\left(39.28^{\circ} \mathrm{N}\right.$; $8.55^{\circ} \mathrm{W}$ and $24 \mathrm{~m}$ elevation) and included maximum and minimum temperatures $\left({ }^{\circ} \mathrm{C}\right)$, wind speed $\left(\mathrm{m} \mathrm{s}^{-1}\right)$, global solar radiation $\left(\mathrm{W} \mathrm{m}^{-2}\right)$, relative humidity $(\%)$ and precipitation $(\mathrm{mm})$. Climate in the region has Mediterranean characteristics, with mild rainy winters and dry hot summers. Daily weather data relative to the observations period of 2010-2012 are shown in Fig. 1 including the reference evapotranspiration $\left(\mathrm{ET}_{0}, \mathrm{~mm} \mathrm{~d}^{-1}\right)$ determined with the FAO-PM method (Allen et al., 1998).

Fields were cropped with Zea mays L. hybrid PR33Y74 (FAO 600) with a density of approximately 82,000 plants ha $^{-1}$. Management practices, including fertilization and irrigation, were performed according to the standard practices in the region and were decided by the farmer. Direct sowing was used. Along the three irrigation seasons several fields were followed-up: two fields in 2010 and 2012, respectively, fields 1 and 2, and fields 2 and 3; in 2011 only field 1 was observed. These fields were approximately 30 ha (fields 1 and 2) and 40 ha (field 3). Further information, including crop stages, is given by Paredes et al. (2014a).

The main soil hydraulic properties of the three fields observed are presented in Table 1 . Three undisturbed soil samples of $100 \mathrm{~cm}^{3}$ for each soil layer to a maximum depth of $1 \mathrm{~m}$ were collected prior to the beginning of the experiment to determine the soil water retention curve and the dry bulk density. The soil water retention curve for each layer was determined in the laboratory using suction tables with sand for suctions below $-10 \mathrm{kPa}$, and a pressure plate apparatus for suctions of $-10,-33,-100$ and $-1500 \mathrm{kPa}$ (Ramos et al., 2011; Moreno et al., 2013). The saturated hydraulic conductivity $\left(K_{\mathrm{sat}}, \mathrm{cm} \mathrm{d}^{-1}\right)$ values were obtained using pedotransfer functions of texture and bulk density (Ramos et al., 2014). Soils are Eutric Fluvisols (FAO, 2006). In fields 1 and 2 soils have loamy sand texture and in field 3 the soil has a silt loam texture. The total available water (TAW), difference between the soil water stored at field capacity and at the wilting point to a depth of $1.0 \mathrm{~m}$, is 171 and $149 \mathrm{~mm} \mathrm{~m}^{-1}$ for fields 1 and 2, respectively, 


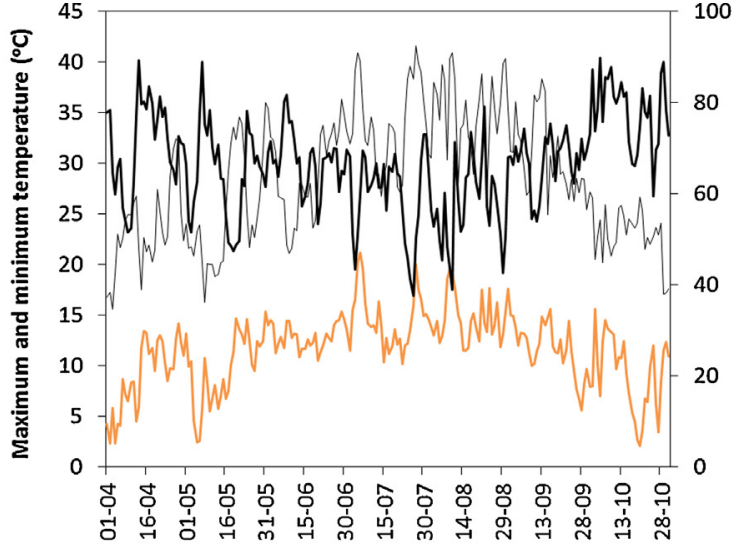

Date

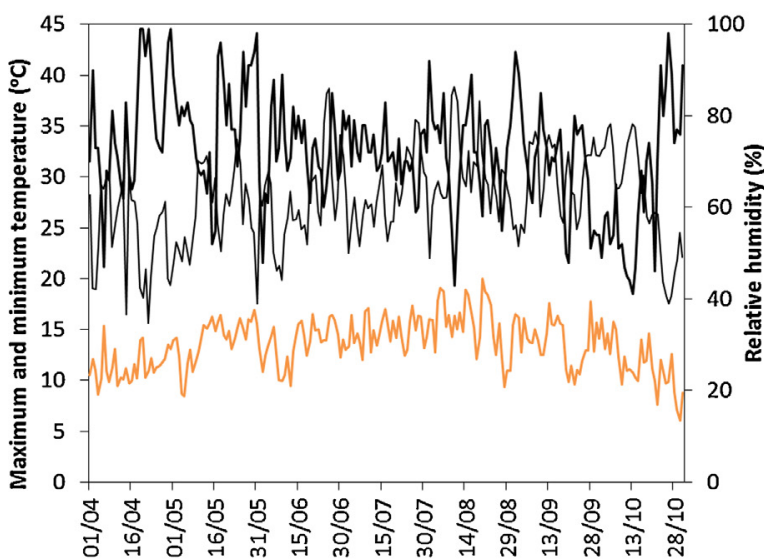

Date

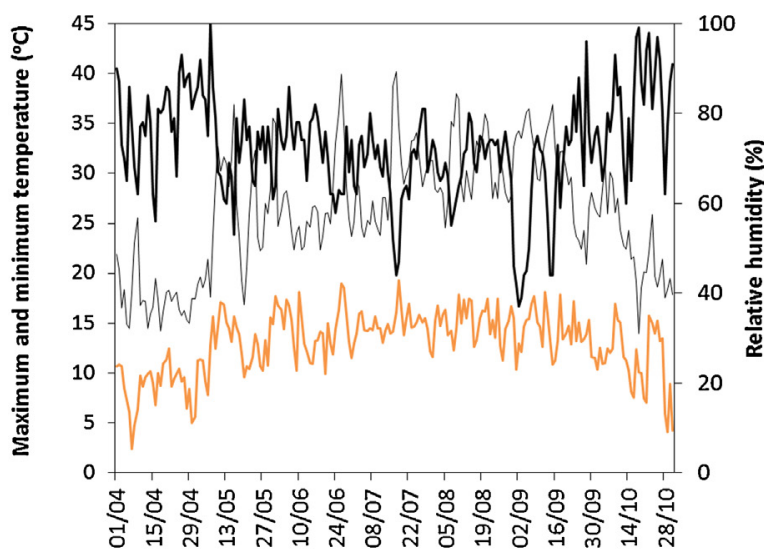

Date

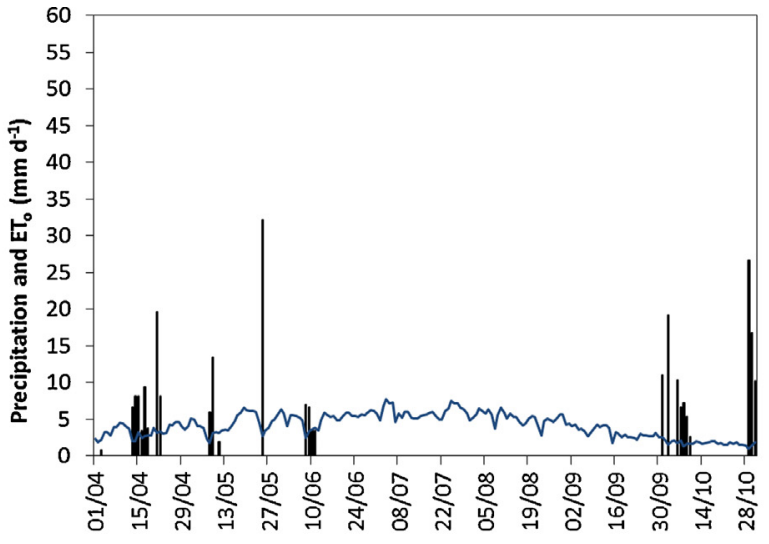

Date

a)

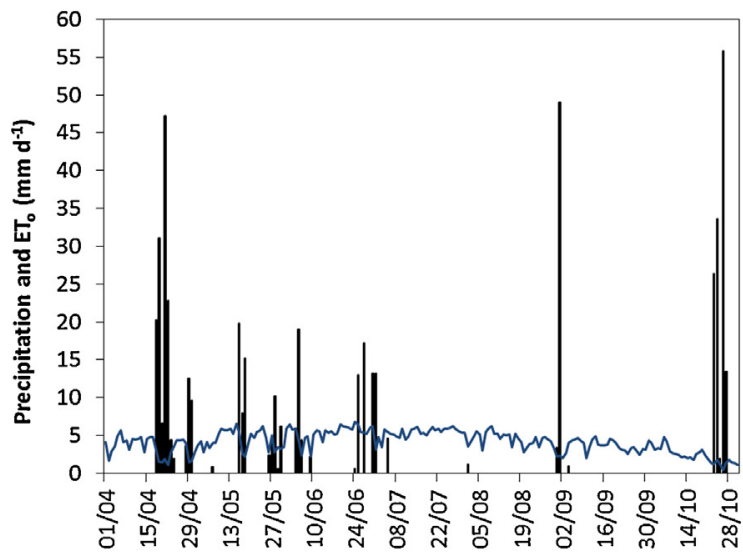

Date

b)

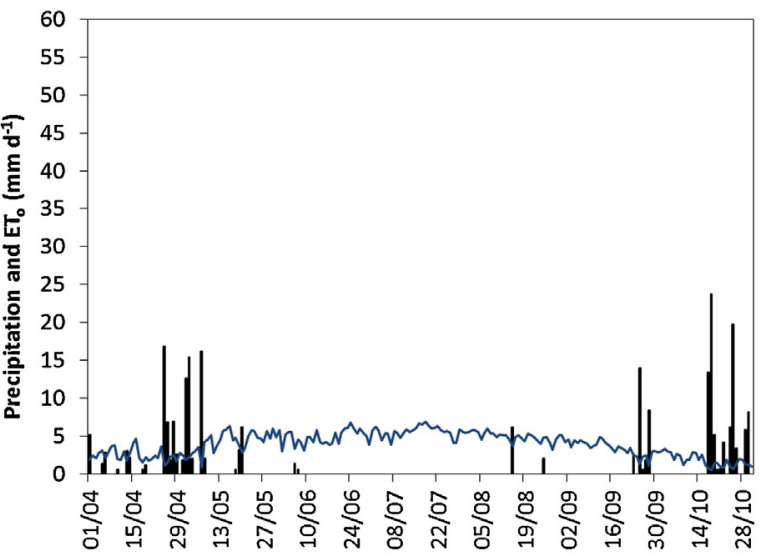

Date

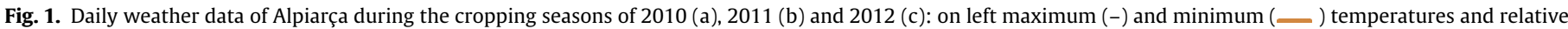
humidity (-); on right precipitation ( $)$ and reference evapotranspiration $\left(\mathrm{ET}_{0}\right)($

Table 1

Selected soil hydraulic properties of the Alpiarça fields.

\begin{tabular}{|c|c|c|c|c|c|c|c|c|c|c|c|c|}
\hline \multirow[t]{2}{*}{ Soil layer (m) } & \multicolumn{3}{|c|}{$\theta_{\mathrm{FC}}\left(\mathrm{m}^{3} \mathrm{~m}^{-3}\right)$} & \multicolumn{3}{|c|}{$\theta_{\mathrm{WP}}\left(\mathrm{m}^{3} \mathrm{~m}^{-3}\right)$} & \multicolumn{3}{|c|}{$\theta_{\text {sat }}\left(\mathrm{m}^{3} \mathrm{~m}^{-3}\right)$} & \multicolumn{3}{|c|}{$K_{\text {sat }}\left(\mathrm{cm} \mathrm{d}^{-1}\right)$} \\
\hline & Field 1 & Field 2 & Field 3 & Field 1 & Field 2 & Field 3 & Field 1 & Field 2 & Field 3 & Field 1 & Field 2 & Field 3 \\
\hline $0.00-0.10$ & 0.32 & 0.25 & 0.35 & 0.08 & 0.08 & 0.22 & 0.48 & 0.56 & 0.45 & 442 & 891 & 71 \\
\hline $0.10-0.20$ & 0.25 & 0.17 & 0.36 & 0.06 & 0.05 & 0.24 & 0.35 & 0.39 & 0.41 & 129 & 157 & 46 \\
\hline $0.20-0.40$ & 0.22 & 0.17 & 0.36 & 0.06 & 0.04 & 0.20 & 0.33 & 0.36 & 0.42 & 93 & 117 & 50 \\
\hline $0.40-0.60$ & 0.22 & 0.26 & 0.37 & 0.04 & 0.09 & 0.12 & 0.34 & 0.32 & 0.43 & 87 & 40 & 59 \\
\hline $0.60-0.80$ & 0.22 & 0.16 & 0.36 & 0.05 & 0.04 & 0.10 & 0.34 & 0.36 & 0.43 & 93 & 86 & 61 \\
\hline $0.80-1.00$ & 0.17 & 0.32 & 0.37 & 0.04 & 0.14 & 0.12 & 0.24 & 0.39 & 0.45 & 92 & 66 & 77 \\
\hline
\end{tabular}

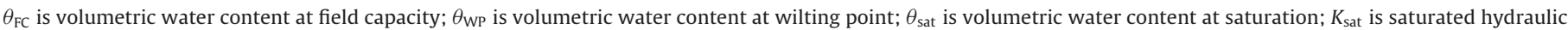
conductivity. 

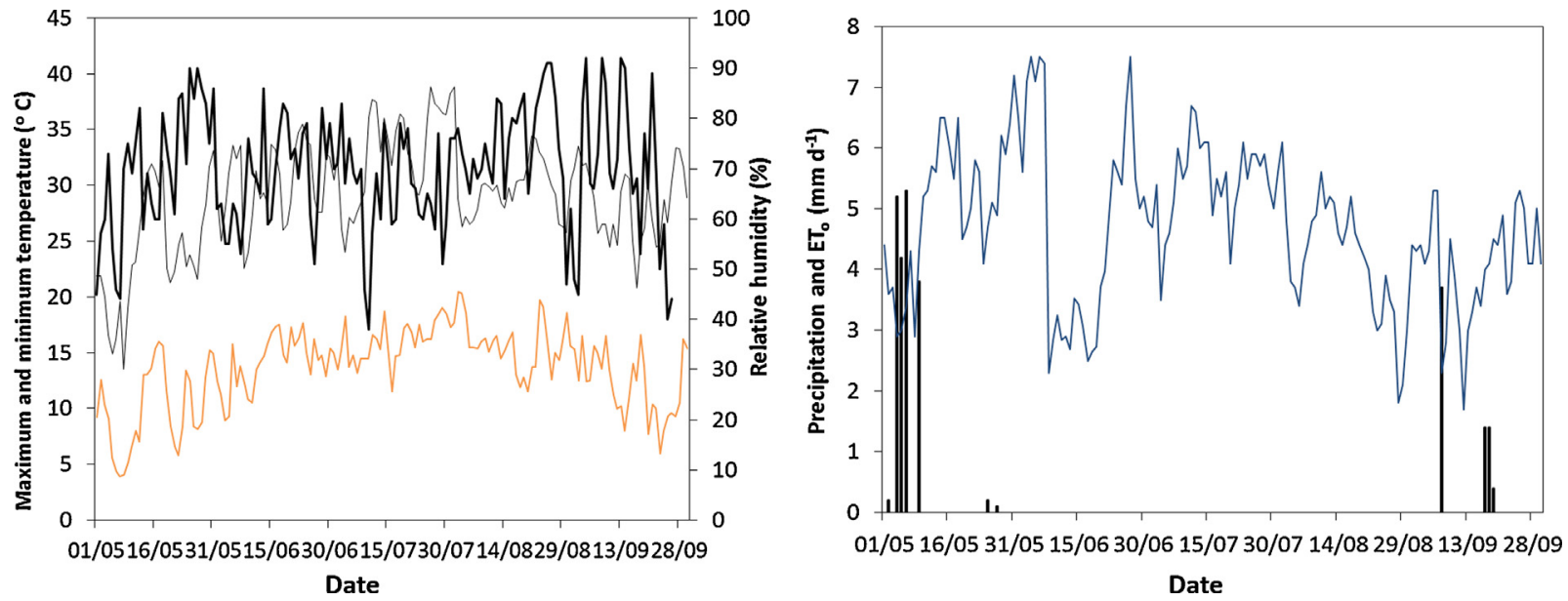

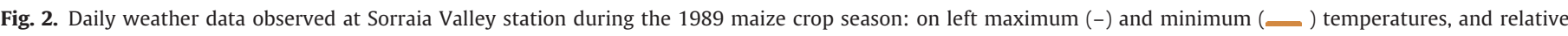
humidity (-); on right precipitation ( $\mathbf{\square})$ and reference evapotranspiration (ETo $(-)$ ).

and TAW $=209 \mathrm{~mm} \mathrm{~m}^{-1}$ for field 3 . The saturated hydraulic conductivity $\left(K_{\mathrm{sat}}, \mathrm{cm} \mathrm{d}^{-1}\right)$ was moderate for the entire profile except for the top $0.10 \mathrm{~m}$ (Table 1 ) where higher values are associated with moderate to high organic matter content, averaging 25,30 and $26 \mathrm{mg} \mathrm{g}^{-1}$ for fields 1,2 and 3, respectively. This is due to manure additions performed two weeks prior to sowing and also to crop residues from the previous crop season because direct sowing is practiced. The $K_{\text {sat }}$ values (Table 1 ) are near the range proposed by Rawls et al. (1998) and Raes et al. (2012) for loamy sand and silt loam soils. A full description of the soils textural properties is presented by Paredes et al. (2014a). Groundwater is below $10 \mathrm{~m}$ and therefore capillary rise does not influence the moisture conditions in the maize root zone.

Field observations included:

(i) dates of most relevant crop growth stages;

(ii) rooting depths, observed using a $1 \mathrm{~m}$ probe in random points between emergence and maximum canopy cover;

(iii) leaf area index $\left(\mathrm{LAI}, \mathrm{m}^{2} \mathrm{~m}^{-2}\right)$, measured along the crop season, usually with a 7-day interval, at three locations per field using a ceptometer (Decagon Devices Inc. USA, model AccuPAR LP-80) and following the recommendations proposed by Johnson et al. (2010). LAI measurements in 2010 were lost due to problems with the logger incorporated in the ceptometer;

(iv) biomass samples and the final actual yield observed at harvesting: samples were composed of 10 plants harvested near each soil water probe access tube (see (vi) below). Samples were placed in refrigerator containers for transporting to the lab, where they were separated into leaves, stem, cob and grains; samples were weighted to obtain fresh weight and then oven dried to constant weight at $65 \pm 5^{\circ} \mathrm{C}$ to obtain dry weight. The yield was adjusted to $13 \%$ grain moisture as used in other studies (Popova and Pereira, 2011).

(v) irrigation depths $(D, \mathrm{~mm})$, observed with rain gauges placed $0.20 \mathrm{~m}$ above the canopy and near the probe access tubes. All fields were sprinkler irrigated with a center-pivot in fields 1 and 2 and a linear moving system in field 3, both equipped with overhead rotator sprinklers;

(vi) volumetric soil water content, measured during 2010 using previously calibrated EnviroSCAN probes (Sentek Pty. Ltd, Stepney, South Australia) at depths of 0.10, 0.20, 0.30 and $0.50 \mathrm{~m}$, and during 2011 and 2012 with a DIVINER 2000 probe (Sentek Pty. Ltd, Stepney, South Australia), with measurements at each $0.10 \mathrm{~m}$ until $0.90 \mathrm{~m}$ depth. Probes calibration followed manufacturer recommendations and procedures
Table 2

Selected soil hydraulic properties of the Sorraia Valley experimental field.

\begin{tabular}{lllll}
\hline Soil layer $(\mathrm{m})$ & $\theta_{\mathrm{FC}}\left(\mathrm{m}^{3} \mathrm{~m}^{-3}\right)$ & $\theta_{\mathrm{WP}}\left(\mathrm{m}^{3} \mathrm{~m}^{-3}\right)$ & $\theta_{\text {sat }}\left(\mathrm{m}^{3} \mathrm{~m}^{-3}\right)$ & $K_{\text {sat }}\left(\mathrm{cm} \mathrm{d}^{-1}\right)^{*}$ \\
\hline $0.00-0.55$ & 0.22 & 0.075 & 0.37 & 445 \\
\hline
\end{tabular}

$\theta_{\mathrm{FC}}$ is volumetric water content at field capacity; $\theta_{\mathrm{WP}}$ is volumetric water content at wilting point; $\theta_{\text {sat }}$ is volumetric water content at saturation; $K_{\text {sat }}$ is saturated hydraulic conductivity.

Cameira et al. (2003)

(Sentek, 2001) and therefore a calibration curve was obtained for each field. Observations were generally performed twice a week at 16 locations per field.

A more detailed description of the experiments is given in Paredes et al. (2014a).

\subsubsection{Deficit irrigation trials}

Experiments were performed in 1989 at the António Teixeira Experimental Station, located in the Sorraia Valley, Coruche, Central Portugal. These fields are inside a 15,000 ha irrigation district. The experiments were set with the objective of assessing the impacts on maize yields at various levels of deficit irrigation at different crop growth stages. The climate is similar to that of Alpiarça, reported above. Fig. 2 presents main climatic data of the maize crop season including $\mathrm{ET}_{0}$ computed with the FAO-PM method (Allen et al. 1998).

The experiments were performed with $Z$. mays L. hybrid LG18 (FAO 300) with a plant density of approximately 90,000 plants ha ${ }^{-1}$. The maize crop was sown on the 10th May, emergence occurred on 25th May, the maximum canopy cover was reached on 12th to 19th July depending on the irrigation treatment; the start of canopy senescence, which also depended upon the treatment, occurred from the 1st to the 28th August. Harvest was performed on 5th September for all treatments (Alves et al., 1991). The soil characterization is given in Table 2 . These data have been analyzed and used in previous studies (Rodrigues et al., 2013; Paredes et al., 2014a).

Field observations and measurements relative to each treatment included:

(i) dates of most relevant crop growth stages;

(ii) leaf area index (LAI, $\mathrm{m}^{2} \mathrm{~m}^{-2}$ ), measured at key dates of the crop season, using a ceptometer (LI-3000 A, LI-COR, Lincoln, Nebraska, USA). Three measurements were performed during the crop development and four after flowering; 
(iii) final yield at harvesting, using a sampling area of about $1.6 \mathrm{~m}^{2}$ per treatment. Samples were separated into leaves, stem, cob and grains; samples were weighted to obtain fresh weight and then oven dried to constant weight at $65 \pm 5^{\circ} \mathrm{C}$ to obtain the dry weight. Yield was adjusted to $13 \%$ grain moisture.

(iv) irrigation depths $(D, \mathrm{~mm})$ determined using rain gauges placed above the canopy and near the probe access tubes. The irrigation treatments were set using a modified sprinkler linesource technique (Hanks et al., 1976). Irrigation was performed every 5 days during the summer months. Infra-red thermometers allowed to confirm that the plants in the well irrigated field were kept stress free (Jackson, 1982; Alves and Pereira, 2000);

(v) soil water content measured before and after each irrigation event using a previously calibrated neutron probe (DIDCOT, UK) at depths of $0.10,0.15,0.20,0.30,0.40,0.50,0.60,0.80$, 1.00 and $1.20 \mathrm{~m}$. Calibration procedures followed Bell (1976) and Hodgnett (1986). A special calibration of the probe was performed for the surface layers $(0.10,0.15$ and $0.20 \mathrm{~m})$ as proposed by Bell (1976);

(vi) actual crop evapotranspiration $\left(\mathrm{ET}_{\mathrm{c}}\right.$ adj $)$, determined for all periods between two successive irrigation events using a soil water balance following Doorenbos and Pruitt (1977). Deep percolation was estimated from soil water measurements performed below the root depth $(0.60$ to $1.20 \mathrm{~m})$; runoff was null as well as capillary rise.

The irrigation treatments were set using a modified sprinkler line-source technique (Hanks et al., 1976). This technique allows a gradual transition between treatments, the grading of water applied to the crop lead also to gradual effects in the crop.

Several deficit and full irrigation schedules were established considering 3 crop growth stages: vegetative, flowering to yield formation, and maturation/ripening (Alves et al., 1991; Paredes et al., 2014a). Six strategies with several replications were selected from the Alves et al. (1991) data set to perform the present study:

(A) full irrigation in all crop growth stages;

(B) water stress imposed during the vegetative stage only;

(C) water stress imposed during maturation/ripening only;

(D) water stress imposed during the vegetative and flowering stages;

(E) water stress imposed during vegetative growth and maturation/ripening; and

(F) water stress imposed along the entire crop season.

Further information is given by Paredes et al. (2014a).

\subsection{The AquaCrop model}

The AquaCrop model (Steduto et al., 2012; Raes et al., 2012) is a crop growth model which combines four sub-models: (1) the soil water balance; (2) the crop development, growth and yield; (3) the atmosphere sub-model, handling rainfall, evaporative demand (reference evapotranspiration, $\mathrm{ET}_{\mathrm{o}}$ ) and $\mathrm{CO}_{2}$ concentration; (4) and the management sub-model, which includes irrigation and fertilization (Raes et al., 2012).

The model computes daily crop evapotranspiration $\left(\mathrm{ET}_{\mathrm{c}}\right.$, $\left.\mathrm{mm} \mathrm{d}^{-1}\right)$ separating crop transpiration $\left(T_{C}, \mathrm{~mm} \mathrm{~d}^{-1}\right)$ and soil evaporation $\left(E_{s}, \mathrm{~mm} \mathrm{~d}^{-1}\right) . T_{c}$ is given as (Raes et al., 2012)

$T_{c}=\mathrm{CC}^{*} K_{c \operatorname{Tr}, x} \mathrm{ET}_{\mathrm{o}}$

where $\mathrm{ET}_{\mathrm{o}}$ is reference evapotranspiration ( $\left.\mathrm{mm}\right), K_{c \mathrm{Tr}, x}$ is the maximum standard crop transpiration coefficient (non-dimensional), and $\mathrm{CC}^{*}$ is the actual crop canopy cover (\%) adjusted for microadvective effects. The actual (or adjusted) transpiration $\left(T_{a}\right)$ is obtained by adjusting $T_{C}$ to soil water stress conditions using the water stress coefficient $K_{s}(0-1)$, i.e., $T_{a}=K_{s} T_{c}$. The coefficient $K_{s}$ describes the effects of soil water stress on the following crop growth processes (Raes et al., 2012): (i) reduction of the canopy expansion rate; (ii) acceleration of senescence; (iii) closure of stomata; and (iv) changes in the harvest index (HI) after the start of the reproductive growth. $K_{c T r, x}$ is adjusted by the model to take into consideration ageing effects and senescence.

The soil evaporation is also obtained from $\mathrm{CC}^{*}$ and $\mathrm{ET}_{\mathrm{o}}$ as:

$E_{S}=K_{r}\left(1-\mathrm{CC}^{*}\right) K_{\mathrm{ex}} \mathrm{ET}_{\mathrm{o}}$

where $K_{\mathrm{ex}}$ is the maximum soil evaporation coefficient (nondimensional) and $K_{r}$ is the evaporation reduction coefficient $(0-1)$, with $K_{r}<1$ when insufficient water is available in the top soil to respond to the evaporative demand of the atmosphere. $K_{\text {ex }}$ can be adjusted for withered canopy, for mulches and for partial wettings following the FAO56 approach (Allen et al., 1998).

The above ground dry biomass $\left(B\right.$, tha $\left.^{-1}\right)$ is estimated by the model using the water transpired by the crop along the season and the adjusted biomass (water) productivity (BWP*, $\mathrm{g} \mathrm{m}^{-2}$ ). BWP* represents the above ground biomass produced per unit of land area considering both the cumulative transpiration, after adjustment for atmospheric $\mathrm{CO}_{2}$ concentration, and $\mathrm{ET}_{0}$ (Raes et al., 2012). A semiempiric approach is used to compute the crop yield $\left(Y, \mathrm{tha}^{-1}\right)$ from $B$ as:

$Y=f_{\mathrm{HI}_{\mathrm{I}}} \mathrm{HI}_{\mathrm{O}} B$

where $\mathrm{HI}_{\mathrm{O}}$ is the reference harvest index, which indicates the harvestable proportion of biomass, and $f_{\mathrm{HI}}$ is an adjustment factor integrating five water stress factors relative to the inhibition of leaf growth, inhibition of stomata, reduction in green canopy duration due to senescence, reduction in biomass due to pre-anthesis stress, and pollination failure (Raes et al., 2012).

In the present study, $\mathrm{HI}_{\mathrm{O}}$ was observed in all seasons in no stress conditions and averaged 0.49 and 0.48 for the Alpiarça and Sorraia Valley sites, respectively. This averaging approach follows those adopted in other AquaCrop studies (Araya et al., 2010; Zeleke et al., 2011). Our $\mathrm{HI}_{0}$ values are in the range of those reported by Di Paolo and Rinaldi (2008) [0.36-0.53], Heng et al. (2009) and Hsiao et al. (2009) [0.48], Farré and Faci (2009) [0.16-0.51] and Katerji et al. (2013) who found a value of 0.46 .

The model input data (Raes et al., 2012) includes:

(1) Daily weather data on maximum and minimum air temperatures $\left({ }^{\circ} \mathrm{C}\right)$, precipitation, $P_{e}(\mathrm{~mm})$, reference evapotranspiration, $\mathrm{ET}_{\mathrm{o}}(\mathrm{mm})$; atmosphere data refer to annual $\mathrm{CO}_{2}$ concentration.

(2) Crop data referring to: (i) the dates of emergence, when maximum canopy cover is reached, when maximum root depth is attained, when canopy senescence starts, when maturity is reached, when flowering starts and ends; (ii) maximum value of the transpiration crop coefficient $\left(K_{c T r, x}\right)$; (iii) minimum and maximum root depths $Z_{r}(\mathrm{~m})$ and roots expansion shape factor; (iv) the initial and maximum crop canopy cover $\left(\mathrm{CC}_{0}\right.$, $\mathrm{CC}_{\mathrm{x}}$ ), canopy growth coefficient (CGC) and the canopy decline coefficient (CDC); (v) adjustment biomass (water) productivity $\left(\mathrm{BWP}^{*}\right)$; (vi) reference harvest index $\left(\mathrm{HI}_{\mathrm{O}}\right)$, (vii) water stress coefficients relative to canopy expansion, stomatal closure, early canopy senescence and aeration stress due to waterlogging.

(3) Soil data for a multi-layered soil including a maximum of 5 layers. For each layer data refer to layer depth $d(m)$, soil water content at field capacity $\theta_{\mathrm{FC}}\left(\mathrm{m}^{3} \mathrm{~m}^{-3}\right)$, at the wilting point $\theta_{\mathrm{WP}}$ $\left(\mathrm{m}^{3} \mathrm{~m}^{-3}\right)$ and at saturation $\theta_{\text {sat }}\left(\mathrm{m}^{3} \mathrm{~m}^{-3}\right)$, and the saturated hydraulic conductivity $\left(K_{\mathrm{sat}}\right)$. Relative to the soil profile, data 
refer to the readily evaporable soil water (REW, $\mathrm{mm}$ ) and the curve number $(\mathrm{CN})$.

(4) Irrigation scheduling data, both dates and depths of observed irrigation events or, when the model is used to generate irrigation schedules, the soil water thresholds and irrigation depths and frequency.

(5) Field management practices relative to salinity, soil fertility, mulching and runoff reduction practices.

The canopy cover (CC) is equivalent to the fraction of soil covered by the canopy $\left(f_{c}\right.$, non-dimensional) in FAO56 (Allen et al., 1998); however, the model does not allow using observed data to build the CC curve but allows to calibrate the CC curves. Model computations of CC are performed through three phases (Raes et al., 2012): the first one uses an exponential function of time, which begins at crop emergence and ends when half of the maximum CC is reached, with the CC growth rate defined by the parameter CGC; the second phase uses another exponential function until the maximum $C C\left(C_{X}\right)$ is reached, with the shape given by the same CGC parameter; the last phase refers to the decline of green canopy cover after senescence starts and its shape is defined by the parameter CDC (Raes et al., 2012). To parameterize the CC curves ( $C_{\mathrm{x}}$, CGC and CDC) observed LAI values may be used to compute the corresponding CC values with an exponential time decay function (Hsiao et al., 2009):

$\mathrm{CC}=1.005[1-\exp (-0.6 \mathrm{LAI})]^{1.2}$

Further descriptions of the model and auxiliary equations are given by Raes et al. (2012).

\subsection{Model parameterization, calibration and validation}

The AquaCrop model uses a large number of parameters including several conservative ones that are expected to change little with time, management or location, and are described and tabled by Raes et al. (2012). These tabled values were used together with other conservative parameters obtained for maize based on field experiments reported by Hsiao et al. (2009) and Heng et al. (2009). The model was first parameterized for appropriately describing the CC curve given its great importance to model both transpiration and soil evaporation (Eqs. (1) and (2)). Thus, the trial and error procedure focused first on the parameters that determine the CC curve, i.e., $\mathrm{CC}_{\mathrm{x}}$, CGC and CDC. Specific parameters values were searched for each year and treatment. Subsequently, the trial and error procedure focused on adjusting the $K_{c T r, x}$, as well as REW and $\mathrm{CN}$, by comparing simulated and observed field data of available soil water (ASW) or/and ET. In this application, the REW and $\mathrm{CN}$ for Alpiarça were those obtained in a previous study with the SIMDualKc model (Paredes et al., 2014a). BWP* for Alpiarça and Sorraia Valley case studies were 33.7 and $32.3 \mathrm{~g} \mathrm{~m}^{-2}$, respectively, in agreement with the values proposed by Hsiao et al. (2009). The model was calibrated with the Alpiarça data of 2011 and was tested with data collected in 2010 and 2012 and data of all the Sorraia treatments.

To assess the "goodness-of-fit" of the model, various statistical approaches were used, as in previous studies (Rosa et al., 2012; Paredes et al., 2014a). The first approach refers to the linear regression forced through the origin relating observed and predicted values; the respective regression and determination coefficients are used as indicators. A regression coefficient $(b)$ close to 1.0 indicates that the predicted values are statistically close to the observed ones; a determination coefficient $\left(R^{2}\right)$ close to 1.0 indicates that most of the variance of the observed values is explained by the model.

A set of indicators of residual estimation errors was also used (Moriasi et al., 2007): the root mean square error (RMSE), which expresses the variance of errors, and the average absolute error
(AAE), that expresses the average size of the estimate errors. These indicators are computed from the pairs of observed and predicted values $O_{i}$ and $P_{i}(i=1,2, \ldots, n)$ whose means are, respectively, $\bar{O}$ and $\bar{P}$, thus:

RMSE $=\left[\frac{\sum_{i=1}^{n}\left(P_{i}-O_{i}\right)^{2}}{n}\right]^{0.5}$

and

$\mathrm{AAE}=\frac{1}{n} \sum_{i=1}^{n}\left|O_{i}-P_{i}\right|$

To test the quality of the modelling approach the Nash and Sutcliffe (1970) modelling efficiency (EF, non-dimensional) was used. It is a normalized statistic that determines the relative magnitude of the residual variance compared to the measured data variance (Moriasi et al., 2007) and is defined as:

$\mathrm{EF}=1.0-\frac{\sum_{i=1}^{n}\left(O_{i}-P_{i}\right)^{2}}{\sum_{i=1}^{n}\left(O_{i}-\bar{O}\right)^{2}}$

EF approaches 1.0 when the residual variance is much smaller than the measured data variance, while negative $\mathrm{EF}$ values indicate that the mean is a better estimator than the model (Moriasi et al., 2007).

\section{Results and discussion}

\subsection{Model performance when applied to real farming maize production}

\subsubsection{Canopy cover curve}

The observed maize data on crop growth stages, roots depths and LAI were presented by Paredes et al. (2014a). As previously explained, model calibration was performed by minimizing the differences between observed and simulated available soil water (ASW, mm), biomass and yield relative using data of field 1 in 2011. That calibration was performed after appropriate parameterization of the CC curve. All calibrated values $\left(\mathrm{CC}_{\mathrm{x}}, \mathrm{CGC}, \mathrm{CDC}, K_{\mathrm{CTr}, x}\right.$, $\mathrm{BWP}^{*}, \mathrm{HI}_{\mathrm{o}}$ ) and conservative ones (i.e., relative to parameters that change little with management or location, Raes et al., 2012) are presented in Table 3; the default values used to initiate the model application are also included. The calibrated $K_{c \operatorname{Tr}, x}=1.18$ (Table 3), which corresponds to the basal crop coefficient for the mid season $\left(K_{\mathrm{cb} \text { mid }}\right)$ (Allen et al., 1998), is similar to the one obtained by Abedinpour et al. (2012), $K_{c \operatorname{Tr}, x}=1.15$, but is higher than the one reported by Hsiao et al. (2009) and Heng et al. (2009), $K_{c \operatorname{Tr}, x}=1.05$. The calibrated $K_{c \operatorname{Tr}, x}$ is similar to the $K_{\mathrm{cb} \text { mid }}=1.15$ proposed by Allen et al. (1998), which was also obtained by Paredes et al. (2014a) for the same data set, and in the studies by Zhang et al. (2013). The calibrated $K_{c \operatorname{Tr}, x}$ also compares well with the single crop coefficient values reported by Piccinni et al. (2009) and Gao et al. (2009).

As referred before, an appropriate parameterization of the $\mathrm{CC}$ curve is a major requisite for the model to produce good estimates of soil evaporation, crop transpiration and biomass (Eqs. (1)-(3)) and, hence, good yield predictions. However, this requirement is not properly identified by the model developers (e.g., Hsiao et al., 2009; Heng et al., 2009; Raes et al., 2012) or other authors. As previously referred, observed LAI values were used to compute the CC values (Eq. (4)) that were used for that parameterization. Specific $\mathrm{CC}_{\mathrm{x}}, \mathrm{CGC}$ and $\mathrm{CDC}$ were obtained for each treatment (Table 3 ). Results of the fitted CC curves are shown in Fig. 3 for 2011 and 2012.

The "goodness-of-fit" indicators relative to the CC curves when using default and calibrated parameters are presented in Table 4. Simulation results using default values show a clear 
Table 3

Conservative and calibrated crop parameters of AquaCrop model.

\begin{tabular}{|c|c|c|c|c|c|}
\hline \multirow{2}{*}{$\begin{array}{l}\text { Description } \\
\text { Conservative parameters }\end{array}$} & \multirow[t]{2}{*}{ Units or symbol meaning } & \multicolumn{2}{|l|}{ Value } & & \\
\hline & & Default ${ }^{*}$ & Adopted & & \\
\hline Base temperature & ${ }^{\circ} \mathrm{C}$ & 8 & 8 & & \\
\hline Cut-off temperature & ${ }^{\circ} \mathrm{C}$ & 30 & 30 & & \\
\hline Canopy cover at $90 \%$ emergence $\left(\mathrm{CC}_{0}\right)$ & $\mathrm{cm}^{2}$ per plant & 6.5 & 4.1 & & \\
\hline Soil water depletion threshold for canopy expansion & Upper threshold & 0.14 & 0.14 & & \\
\hline Soil water depletion threshold for canopy expansion & Lower threshold & 0.72 & 0.72 & & \\
\hline Shape factor for water stress coefficient for canopy expansion & Curve shape moderately convex curve & 2.9 & 2.9 & & \\
\hline Soil water depletion threshold for stomatal control & $\begin{array}{l}\text { Fraction of TAW at which stomata start } \\
\text { to close }\end{array}$ & 0.69 & 0.69 & & \\
\hline Shape factor for water stress coefficient for stomatal control & Highly convex curve & 6.0 & 6.0 & & \\
\hline Soil water depletion threshold for failure of pollination & $\begin{array}{l}\text { Fraction of TAW at which pollination } \\
\text { starts to fail }\end{array}$ & 0.80 & 0.80 & & \\
\hline Calibrated parameters & & Default & Calibrated & & \\
\hline Crop coefficient for transpiration at $\mathrm{CC}_{\mathrm{x}}$ & Basal crop coefficient $\left(K_{\mathrm{cTr}, \mathrm{x}}\right)$ & 1.05 & 1.18 & & \\
\hline BWP* & $\begin{array}{l}\text { Biomass (water) productivity adjusted } \\
\text { for } \mathrm{ET}_{\mathrm{o}} \text { and } \mathrm{CO}_{2}\left(\mathrm{~g} \mathrm{~m}^{-2}\right)\end{array}$ & 33.7 & 33.7 & & \\
\hline $\mathrm{HI}_{\mathrm{O}}$ & Reference harvest index (\%) & 0.50 & 0.49 & & \\
\hline Canopy cover curve parameters & & Default & 2010 & 2011 & 2012 \\
\hline Maximum canopy cover, CCx, & $\%$ & 97 & 96 & 96 & 96 \\
\hline Canopy growth coefficient, CGC & $\% \mathrm{GDD}^{-1}$ & 1.30 & 1.49 & 1.49 & 1.56 \\
\hline Canopy decline coefficient, CDC & $\% \mathrm{GDD}^{-1}$ & 1.06 & 0.40 & 0.35 & 0.43 \\
\hline
\end{tabular}

* Default parameters are tabled by Raes et al. (2012)

tendency for under-estimation of the observed CC values, with the regression coefficient $b<0.95$ for all cases, high estimation errors (RMSE $>16.6 \%$ and AAE $>10.5 \%$ ) and low to medium model efficiency (EF ranging 0.18 to 0.71 ). Differently, when a proper calibration of the CC curve parameters $\left(\mathrm{CC}_{0}, \mathrm{CC}_{\mathrm{x}}, \mathrm{CGC}\right.$ and $\left.\mathrm{CDC}\right)$ was performed, results do not show any tendency to over or underestimation ( $b$ ranging from 0.97 to 1.03 ) and the determination coefficients are higher $\left(R^{2}>0.96\right)$, thus indicating that the CC model highly explains the variance of observed CC values. Estimation errors are then small, with RMSE ranging 4.6 to $7.9 \%$ and AAE

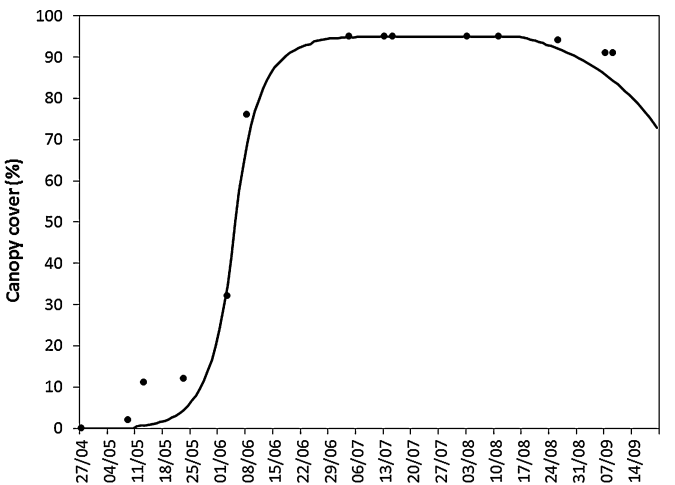

Date

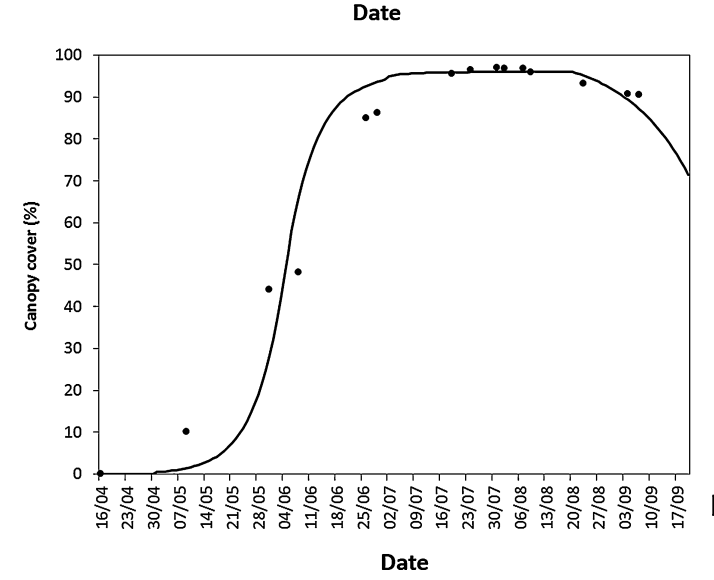

a) varying between 3.1 and 5.3\%. These RMSE values obtained with calibration are in the range or smaller than those reported by Hsiao et al. (2009), with RMSE ranging from 4.8 to $13.6 \%$. García-Vila and Fereres (2012) reported a larger RMSE of approximately 13\% and higher values were reported by Heng et al. (2009) for rainfed maize (7.2 to 34.5\%). High EF values were also obtained (>0.94) which indicate that the residual variance was much smaller than the measured data variance. These results (Table 4) clearly show the need for a careful calibration of the CC curve when searching for accurate results.

Fig. 3. Maize canopy cover (CC) simulated (-) and observed (

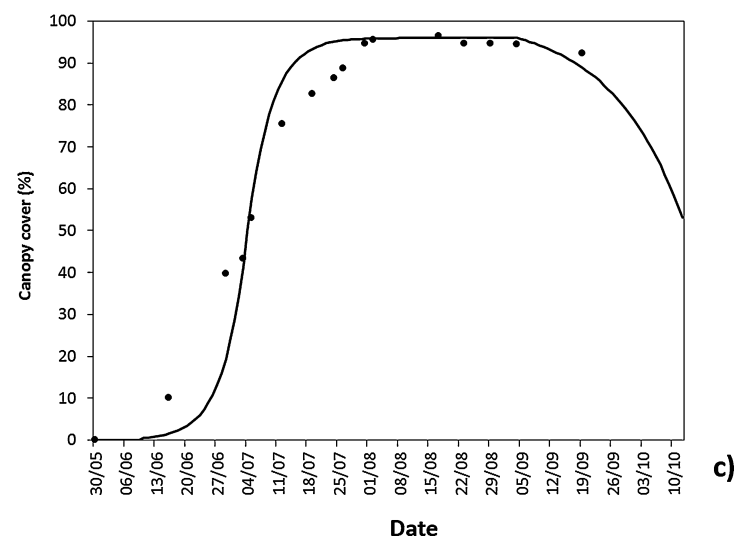

) for Alpiarça: (a) field 1 in 2011, (b) field 2 in 2012 and (c) field 3 in 2012. 
Table 4

"Goodness-of-fit" indicators relative to canopy cover using default and calibrated parameters, Alpiarça case study.

\begin{tabular}{|c|c|c|c|c|c|c|}
\hline & \multirow[t]{2}{*}{ Field and year } & \multicolumn{5}{|c|}{ Goodness of fit indicators } \\
\hline & & $b$ & $R^{2}$ & RMSE (\%) & AAE $(\%)$ & $\mathrm{EF}$ \\
\hline \multirow{4}{*}{ Using default parameters } & Field 1, 2011 & 0.75 & 0.52 & 35.7 & 18.7 & 0.18 \\
\hline & Field 2, 2012 & 0.95 & 0.77 & 18.0 & 10.5 & 0.68 \\
\hline & Field 3, 2012 & 0.93 & 0.87 & 16.6 & 11.0 & 0.71 \\
\hline & All data & 0.88 & 0.69 & 24.5 & 13.2 & 0.49 \\
\hline \multirow{4}{*}{ Using calibrated parameters } & Field 1, 2011 & 0.97 & 0.99 & 4.6 & 3.1 & 0.99 \\
\hline & Field 2, 2012 & 1.01 & 0.96 & 7.2 & 4.5 & 0.95 \\
\hline & Field 3, 2012 & 1.03 & 0.96 & 7.4 & 5.1 & 0.94 \\
\hline & All data & 1.01 & 0.97 & 6.6 & 4.3 & 0.96 \\
\hline
\end{tabular}

\subsubsection{Simulation of the available soil water}

Results of model simulation of the available soil water (ASW) throughout all crop seasons are presented in Fig. 4 when using calibrated, not default parameters. Observations show that stress only occurred during the 2010 season, with the observed ASW falling below the readily available soil water (RAW) threshold during midseason (Fig. 4b and c). Despite adopting a careful parameterization (Section 2.3), the model did not properly simulate ASW. Results in Fig. 4a show a trend for overestimation, which is more important for the lower values of ASW. The same trend for overestimation of lower ASW values is observed for the other simulation results. Contrarily, when ASW are closer to field capacity no trend is observed. These results are somewhat different from those obtained with SIMDualKc model for the same data sets, which are reported by Paredes et al. (2014a) and show a better fit without bias. This indicates that the AquaCrop model does not simulate properly, in particular when soil water deficits occur.

The "goodness-of-fit" indicators relative to the simulation of ASW using the calibrated parameters (Table 3) and represented in Fig. 4 are given in Table 5. Results show regression coefficients ranging from 0.96 to 1.09 and determination coefficients ranging from 0.59 to 0.88 , with $R^{2}=0.88$ for the calibration (field 1,2011 ). These results indicate that a bias of estimation occurred for all experiments. Differently, SIMDualKc results (Table 5) have shown b values ranging from 0.98 to 1.01 and $R^{2}$ ranging from 0.79 to 0.94 . Estimation errors with AquaCrop are relatively low, with RMSE ranging from 8.4 to $11.7 \mathrm{~mm}$, which correspond to a variation of 5.1 to $13.5 \%$ of the total available soil water (TAW), and the AAE values are also small, less than $8.8 \mathrm{~mm}$. However, smaller errors were obtained with SIMDualKc, with RMSE from 4.0 to $6.5 \mathrm{~mm}$. The modelling efficiency with AquaCrop is generally acceptable, with EF from 0.57 to 0.72 , except for field 2 in 2012 where $E F=0.03$. This value indicates that the residuals variance is close to the measured data variance; contrarily, results for the other data sets indicate that the residuals variance is lower than the measured data variance. However, the indicators of "goodness-of-fit" failed the limits for $R^{2}$ and $\mathrm{EF}$, respectively, 0.80 and 0.70 , proposed by Ma et al. (2011) for crop models. Using SIMDualKc (Table 5), EF varied from 0.74 to 0.92 , thus above the limits suggested by Ma et al. (2011). Thus, results indicate that AquaCrop does not accurately simulate ASW.

When using the default parameters given by Raes et al. (2012) and the CC curve is also simulated with default parameters, the "goodness-of-fit" indicators (Table 5 ) show a clear trend for overestimation of ASW $(1.10<b<1.30)$ and the estimation errors are high, with RMSE ranging from 11.6 to $25.7 \%$ of TAW. EF is then generally negative, which indicates that the mean is a better predictor than the simulated values. It can be concluded that a careful parameterization of the CC curve is definitely required when soil water is simulated, and that it is advisable to parameterize the model using accurate soil water observations throughout the crop season.

The poor fitting of the observed ASW when using AquaCrop after model calibration is likely related to the less good estimations of transpiration (Eq. (1)) and soil evaporation (Eq. (2)). Fig. 5 compares $T_{a}$ and $E_{s}$ simulated by AquaCrop and the SIMDualKc model (Paredes et al., 2014a) along the crop seasons of 2010, 2011 and 2012 using the same data sets. Results show that AquaCrop tends to over-estimate $T_{a}$ and to under-estimate $E_{s}$, thus resulting in a bias of estimates of ASW as indicated by the less good EF values in Table 5. Over-estimation of $T_{a}$ is greater when water stress occurs as evidenced when comparing Fig. $5 \mathrm{a}$ and b. Similar differences were also observed and discussed for AquaCrop applications to maize by Katerji et al. (2013), peas (Paredes et al., 2014b) and barley (Paredes et al., 2014c). The over-estimations of $T_{a}$ are due to problems in estimating the adjusted basal crop coefficients in $T_{a}$ computations (Eq. (1)). To verify this assumption, the seasonal variation of the adjusted $K_{\mathrm{cb}}$ calculated with AquaCrop and SIMDualKc are compared in Fig. 6 together with the canopy cover curve simulated by AquaCrop. It can be observed that while $K_{\mathrm{cb} \text { adj }}$ estimated with SIMDualKc follows the classical crop coefficients curve (Allen et al., 1998, 2005; Rosa et al., 2012), the $K_{c T r}$ computed with AquaCrop follow the CC curve (Raes et al., 2012), thus becoming different than the common crop coefficient curves (Fig. 6). Therefore, since the two models follow different conceptual approaches, the adjusted $K_{\mathrm{cb}}$ curves are different, resulting in the AquaCrop $K_{c \operatorname{Tr}}$ not being impacted by water stress if the CC curve itself is not affected by water stress. This is well evident in Fig. 6b where $K_{\mathrm{cb} \text { adj }}$ is highly impacted by water stress early in midseason but $K_{\mathrm{cb} T r}$ is not. Differences among both models, or between AquaCrop and the FAO56 approach, also exist in soil evaporation estimation: while in FAO56 and SIMDualKc $E_{S}$ is daily estimated with a water balance of the evaporative layer (Allen et al., 1998, 2005; Rosa et al., 2012), in AquaCrop $E_{s}$ varies with the CC curve (Eq. (2)). This approach justifies why $E_{S}$ is underestimated when the canopy cover is high, i.e., during mid- and late season. It is also likely a reason for overestimation of low ASW values as referred above. Problems reported for $T_{a}$ and $E_{s}$ estimation are likely to explain the less good "goodness of fit" indicators in Table 5. Therefore, the $K_{c \operatorname{Tr}}$ and CC curve proportionality should be revised since the latter is not sensitive to daily water stress throughout the season but only to water stress during the vegetative stage. An approach similar to that adopted in FAO56 (Allen et al., 1998, 2005) could be considered for estimation of both transpiration and soil evaporation.

\subsection{Model performance for deficit irrigation experiments}

The parameterization of the CC curve was the first focus of the calibration procedure using LAI observations to get observed CC values using Eq. (4). The $\mathrm{CC}_{0}$ value used in the simulation was higher (0.045) than for the Alpiarça studies (Section 3.1) because the plant density was higher in these experiments (see Section 2.1.2). The $C_{x}$ was set as the maximum observed for the full irrigation treatment (0.97); CGC and CDC were set as $2.53 \% \mathrm{GDD}^{-1}$ and $0.72 \% \mathrm{GDD}^{-1}$, respectively. The CGC value is higher than that used for Alpiarça given the hybrid used, of FAO 300 type, that developed faster than 

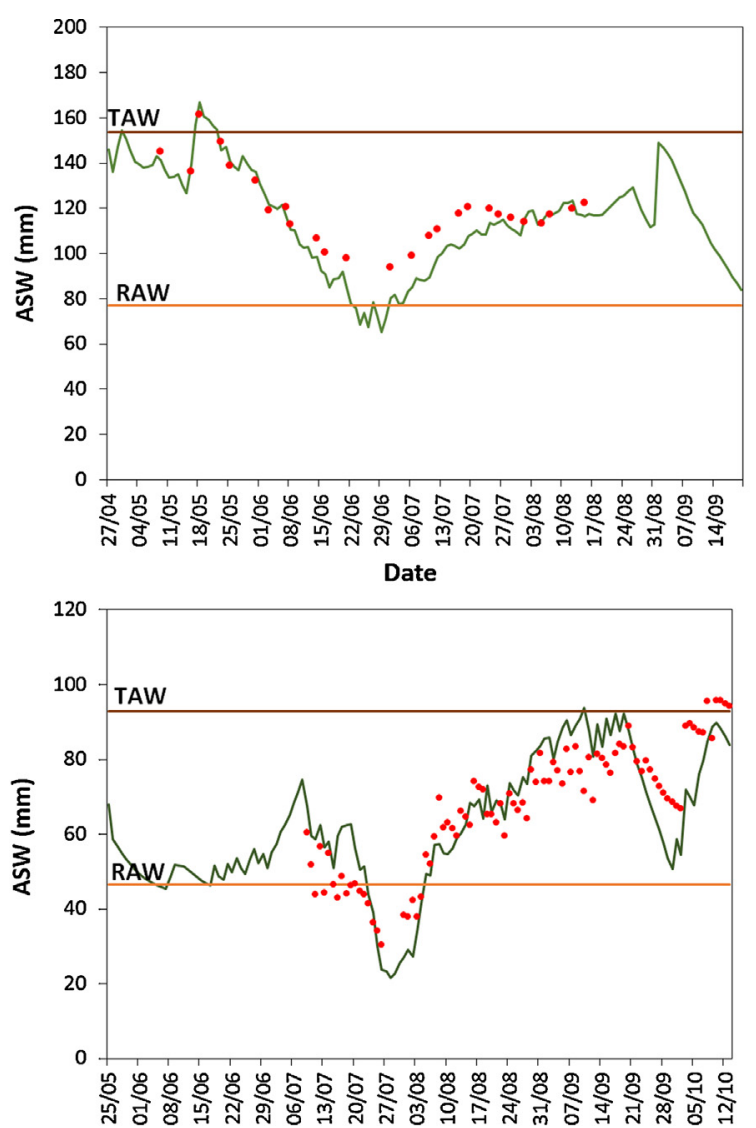

Date

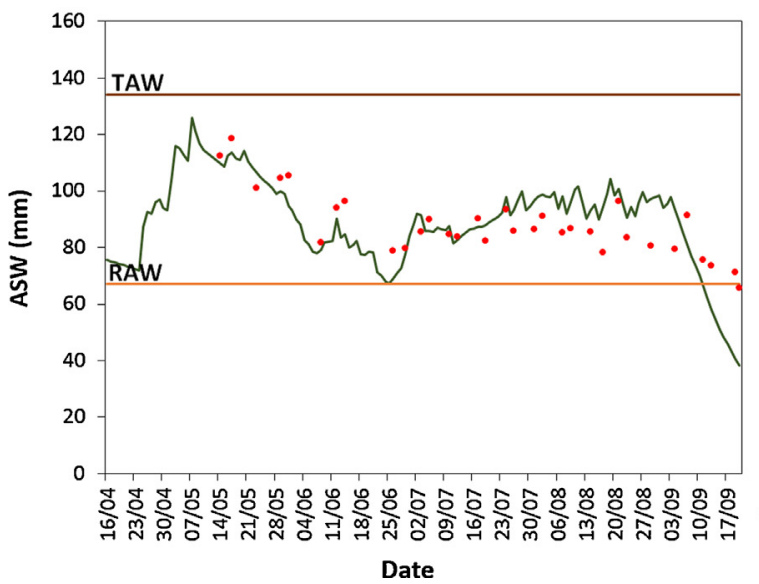

a)
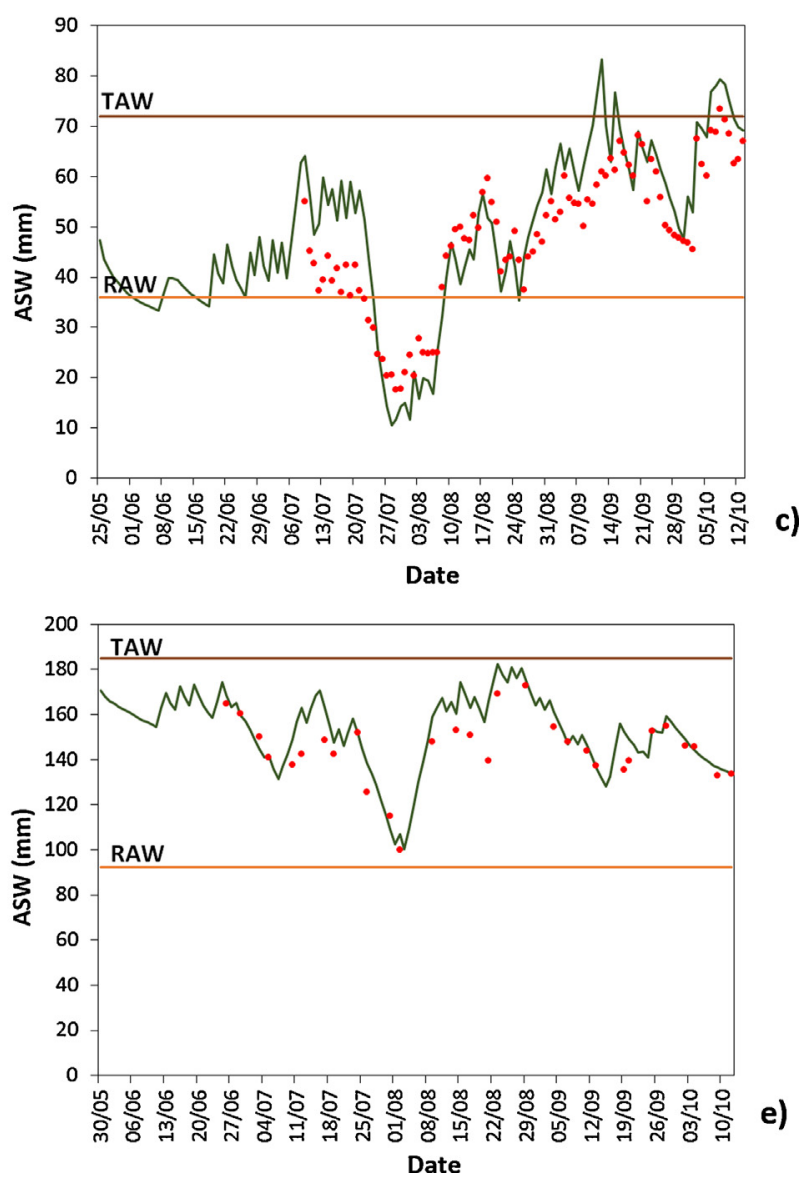

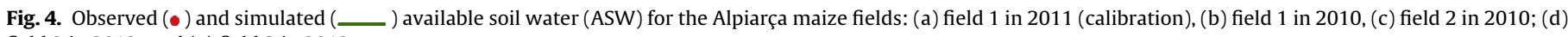
field 2 in 2012; and (e) field 3 in 2012.

the hybrid PR33Y74, of FAO 600 type used at Alpiarça, i.e., requiring 200 GDD less, approximately.

Fig. 7 presents examples of CC curves simulated by AquaCrop relative to each treatment. These results clearly show some discrepancies between simulated and observed CC values during the vegetative development and the mid-season stages, particularly when water stress was imposed during the vegetative stage, i.e., treatments B, D, E and F.

Table 6 presents the "goodness-of-fit" indicators relative to the adjustment of CC curve for every treatment when using both default and calibrated parameters. The model performance is good when using the calibrated CC parameters, with $b$ ranging from 0.96 to 1.03 and $R^{2}$ ranging from 0.80 to 0.96 . The estimation errors are small, with $\mathrm{RMSE}<7 \%$ and $\mathrm{AAE}<6 \%$. $\mathrm{EF}$ are high, ranging from
0.75 to 0.96 , hence indicating that the residuals variance is much smaller than the measured data variance. Contrarily, when using the default parameters, results show a poor model performance, with $b<0.86$ and $R^{2}<0.78$. High estimation errors were found, with RMSE ranging 23.9 to $40.7 \%$ and AAE ranging from 15.3 to $32.2 \%$. Moreover, EF is negative for all treatments, which indicates that the residuals variance is larger than the measured data variance and the modelled values are not appropriate estimators. Overall results show that the model appropriately simulates the CC curve when the parameters are properly calibrated and that, contrarily, the simulations are very inaccurate when using the default parameters.

The AquaCrop was tested for seasonal evapotranspiration calculations comparing, throughout the season, the field estimated 
Table 5

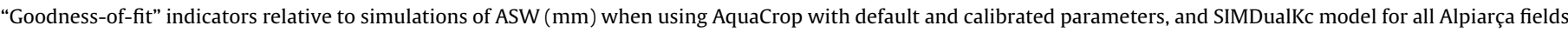
and years.

\begin{tabular}{|c|c|c|c|c|c|c|c|c|c|}
\hline \multirow[t]{2}{*}{ Model } & & \multirow[t]{2}{*}{ Year } & \multirow[t]{2}{*}{ Field } & \multicolumn{6}{|c|}{ Goodness of fit indicators } \\
\hline & & & & $\bar{b}$ & $R^{2}$ & RMSE (mm) & RMSE/TAW (\%) & $\mathrm{AAE}(\mathrm{mm})$ & $\mathrm{EF}$ \\
\hline \multirow[t]{12}{*}{ AquaCrop } & Using default parameters & 2010 & Field 1 & 1.20 & 0.78 & 16.6 & 17.8 & 14.7 & 0.00 \\
\hline & & & Field 2 & 1.26 & 0.71 & 16.3 & 22.6 & 13.7 & -0.36 \\
\hline & & 2011 & Field 1 & 1.10 & 0.53 & 17.9 & 11.6 & 13.0 & -0.26 \\
\hline & & 2012 & Field 2 & 1.30 & 0.03 & 34.5 & 25.7 & 29.9 & -8.40 \\
\hline & & & Field 3 & 1.22 & 0.37 & 36.3 & 19.6 & 33.1 & -5.30 \\
\hline & & All data & & 1.21 & 0.89 & 22.3 & & 18.0 & 0.59 \\
\hline & Using calibrated parameters & 2010 & Field 1 & 1.00 & 0.71 & 9.5 & 10.2 & 8.1 & 0.66 \\
\hline & & & Field 2 & 1.09 & 0.80 & 9.1 & 12.6 & 7.4 & 0.58 \\
\hline & & 2011 & Field 1 & 0.96 & 0.88 & 8.4 & 5.5 & 6.7 & 0.72 \\
\hline & & 2012 & Field 2 & 0.96 & 0.59 & 11.7 & 8.7 & 8.8 & 0.03 \\
\hline & & & Field 3 & 1.04 & 0.79 & 9.5 & 5.1 & 7.1 & 0.57 \\
\hline & & All data & & 1.02 & 0.93 & 9.5 & & 7.7 & 0.93 \\
\hline \multirow[t]{6}{*}{ SIMDualKc(Paredes et al., 2014a) } & & 2010 & Field 1 & 1.01 & 0.92 & 4.8 & 3.1 & 3.9 & 0.91 \\
\hline & & & Field 2 & 1.00 & 0.94 & 4.0 & 3.1 & 3.2 & 0.92 \\
\hline & & 2011 & Field 1 & 0.99 & 0.85 & 6.3 & 4.1 & 5.5 & 0.84 \\
\hline & & 2012 & Field 2 & 0.98 & 0.79 & 5.7 & 4.3 & 4.7 & 0.74 \\
\hline & & & Field 3 & 0.99 & 0.85 & 6.5 & 3.5 & 5.7 & 0.80 \\
\hline & & All data & & 1.00 & 0.98 & 5.0 & & 4.1 & 0.98 \\
\hline
\end{tabular}

Table 6

"Goodness-of-fit" indicators relative to AquaCrop adjustment of CC curve for all treatments when using the default and calibrated parameters, Sorraia Valley.

\begin{tabular}{|c|c|c|c|c|c|c|}
\hline & \multirow[t]{2}{*}{ Treatment } & \multicolumn{5}{|c|}{ Goodness of fit indicators } \\
\hline & & $b$ & $R^{2}$ & RMSE (\%) & $\mathrm{AAE}(\%)$ & $\mathrm{EF}$ \\
\hline \multirow{7}{*}{ Using default parameters } & A & 0.86 & 0.75 & 27.1 & 16.2 & -2.1 \\
\hline & $\mathrm{B}$ & 0.82 & 0.78 & 26.7 & 18.9 & -2.2 \\
\hline & $\mathrm{C}$ & 0.79 & 0.63 & 30.4 & 20.6 & -2.3 \\
\hline & $\mathrm{D}$ & 0.61 & 0.71 & 38.8 & 31.9 & -7.4 \\
\hline & $\mathrm{E}$ & 0.64 & 0.47 & 40.7 & 32.2 & -5.8 \\
\hline & $\mathrm{F}$ & 0.84 & 0.73 & 23.9 & 15.3 & -0.4 \\
\hline & All data & 0.81 & 0.71 & 28.9 & 19.4 & -1.7 \\
\hline \multirow[t]{7}{*}{ Using calibrated parameters } & A & 1.00 & 0.96 & 3.1 & 2.0 & 0.96 \\
\hline & $\mathrm{B}$ & 0.99 & 0.88 & 5.3 & 3.8 & 0.87 \\
\hline & $\mathrm{C}$ & 1.00 & 0.95 & 3.6 & 2.4 & 0.95 \\
\hline & $\mathrm{D}$ & 1.03 & 0.80 & 6.7 & 5.9 & 0.75 \\
\hline & $\mathrm{E}$ & 0.99 & 0.86 & 5.9 & 4.3 & 0.86 \\
\hline & $\mathrm{F}$ & 0.96 & 0.91 & 6.6 & 5.0 & 0.90 \\
\hline & All data & 0.99 & 0.92 & 5.1 & 3.6 & 0.91 \\
\hline
\end{tabular}

Table 7

"Goodness-of-fit" indicators relative to ET simulations for all treatments when using default and calibrated parameters, Sorraia Valley experiments.

\begin{tabular}{|c|c|c|c|c|c|c|}
\hline & \multirow[t]{2}{*}{ Treatment } & \multicolumn{5}{|c|}{ Goodness of fit indicators } \\
\hline & & $\bar{b}$ & $R^{2}$ & RMSE (mm) & $\mathrm{AAE}(\mathrm{mm})$ & $\mathrm{EF}$ \\
\hline \multirow{7}{*}{ Using default parameters } & A & 0.91 & 0.89 & 5.0 & 4.0 & 0.87 \\
\hline & B & 0.93 & 0.75 & 6.6 & 5.0 & 0.72 \\
\hline & $\mathrm{C}$ & 0.91 & 0.87 & 5.7 & 4.9 & 0.85 \\
\hline & $\mathrm{D}$ & 0.87 & 0.59 & 9.7 & 7.8 & 0.47 \\
\hline & $\mathrm{E}$ & 0.88 & 0.60 & 8.6 & 6.4 & 0.49 \\
\hline & $\mathrm{F}$ & 0.97 & 0.71 & 6.9 & 5.2 & 0.67 \\
\hline & All treatments & 0.92 & 0.77 & 6.6 & 5.0 & 0.74 \\
\hline \multirow[t]{7}{*}{ Using calibrated parameters } & A & 1.02 & 0.88 & 5.1 & 4.0 & 0.86 \\
\hline & $\mathrm{B}$ & 1.02 & 0.83 & 5.4 & 3.9 & 0.82 \\
\hline & $\mathrm{C}$ & 1.02 & 0.89 & 5.2 & 4.4 & 0.87 \\
\hline & $\mathrm{D}$ & 0.98 & 0.76 & 6.7 & 5.3 & 0.75 \\
\hline & $\mathrm{E}$ & 1.00 & 0.74 & 6.4 & 4.9 & 0.72 \\
\hline & $\mathrm{F}$ & 1.01 & 0.74 & 6.5 & 4.9 & 0.70 \\
\hline & All treatments & 1.02 & 0.81 & 5.7 & 4.3 & 0.81 \\
\hline
\end{tabular}



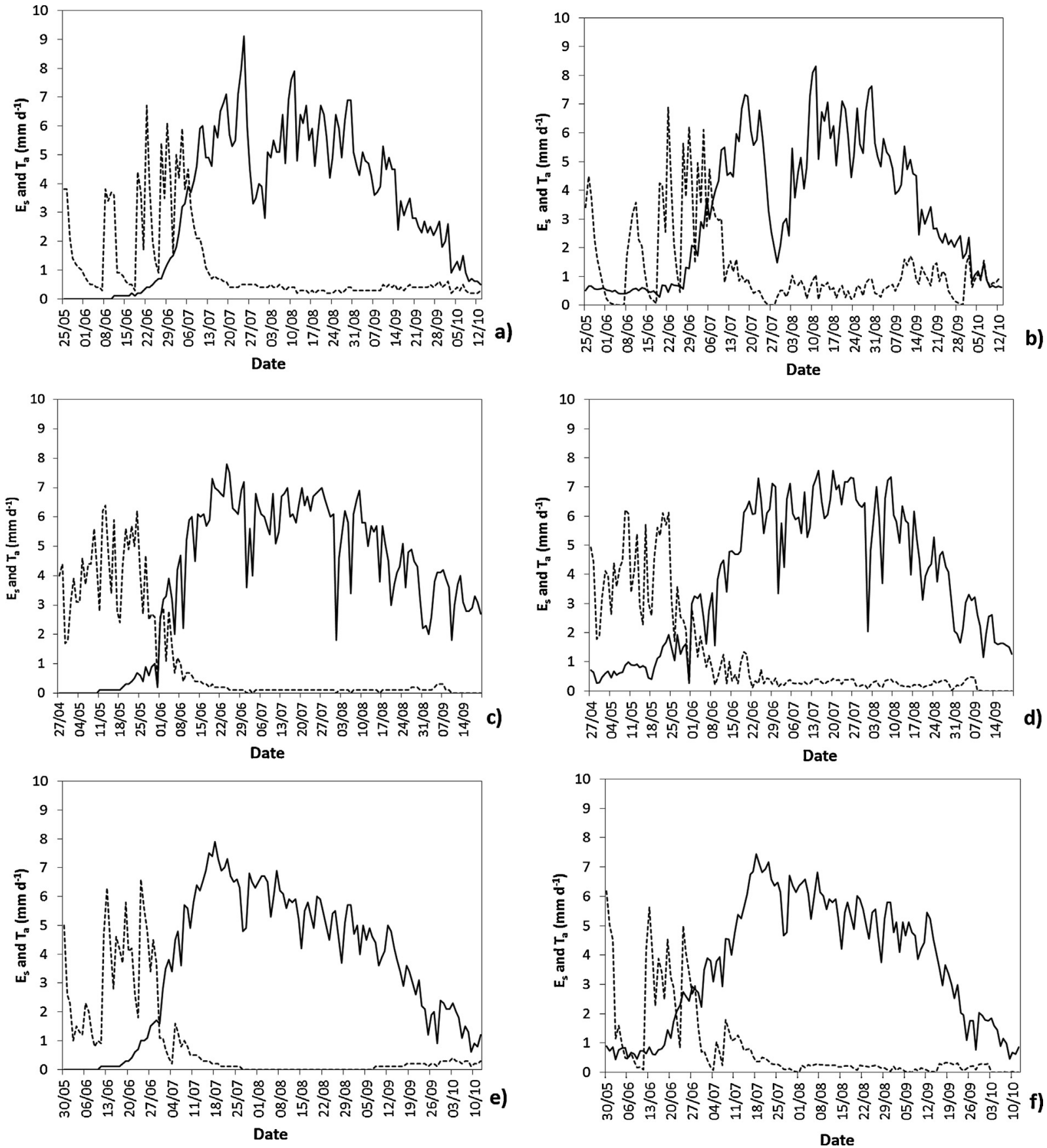

Fig. 5. Seasonal variation of the actual transpiration $\left(T_{a}\right.$, ) and soil evaporation ( $\left.E_{s},-\right)$ in field 2 in 2010 ((a) and (b)), field 1 in 2011 ((c) and (d)), and field 3 in 2012 ((e) and (f)): on left when using AquaCrop and, on right, with the SIMDualKc model.

ET (mm) with model simulations for all treatments. Fig. 8 shows that comparison for selected examples of full irrigation (treatment A), mild deficit irrigation (treatment B) and heavy deficit irrigation (treatment F). Results (Fig. 8 and Table 7) show that the heavy stress treatments present higher RMSE $(6.5 \mathrm{~mm}$ vs. $5.1 \mathrm{~mm})$ but no trends of over- or underestimation of ET were detected ( $b$ ranging from 0.98 to 1.02 ). Contrarily, there is a trend of underestimation of ET when default parameters are used ( $b$ from 0.87 to 0.97 ). EF values are acceptable, ranging 0.70 to 0.87 when calibrated parameters are used. EF values for the case of stressed experiments D to F highly decrease when default parameters are used (Table 7).

Fig. 9 shows examples of the different responses of the adjusted crop coefficient $-K_{c \mathrm{Tr}}$ in case of AquaCrop and $K_{\mathrm{cb} \text { adj }}$ in case of SIMDualKc - to water stress, thus identifying a much larger dependency in case of $K_{\mathrm{cb}}$ adj than for $K_{\mathrm{cTr}}$ because the latter is very much tied to the CC curve. Results show that in AquaCrop the impacts of water stress on transpiration are minimized due to the dependency of $K_{c \operatorname{Tr}}$ and $T_{a}$ upon CC, as discussed before. Contrarily, when adopting the approach by FAO56 that is considered in SIMDualKc (Allen et al., 1998, 2005; Rosa et al., 2012), $K_{\mathrm{cb} \text { adj }}$ is sensitive to water stress. Following discussions in Section 3.1, it can also be concluded that the $K_{c T r}$ and CC curve proportionality should be revised and an approach similar to that adopted in FAO56 could be considered. These results indicate that model computations of the actual ET are less sensitive to the CC curve than soil water computations because the over-estimations of $T_{a}$ partly compensates for the underestimation of $E_{s}$, thus resulting in small differences between estimated and observed ET. 


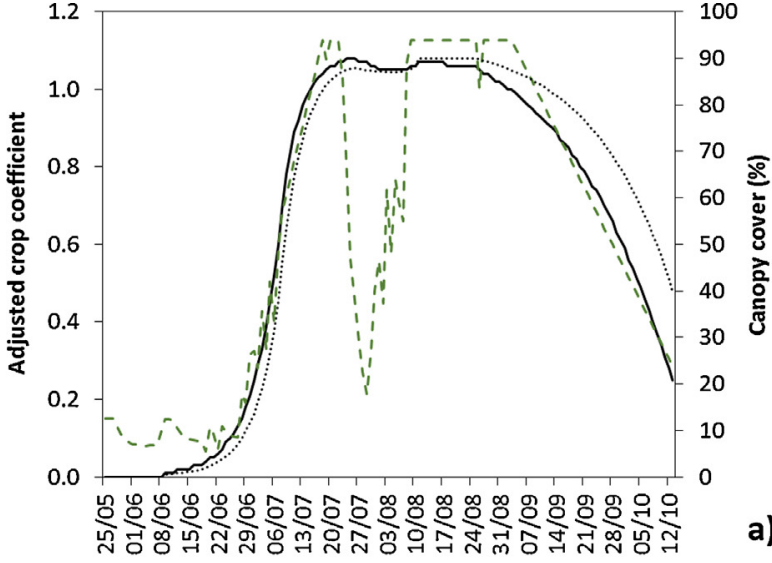

Date

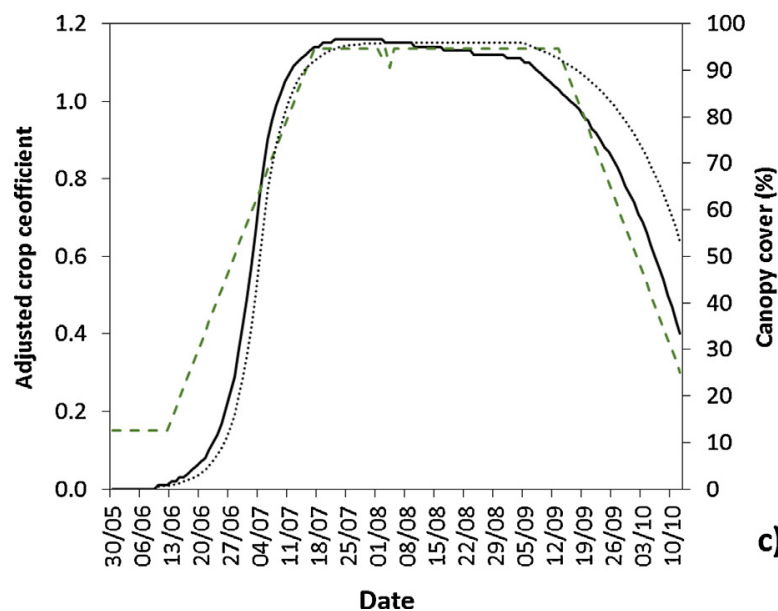

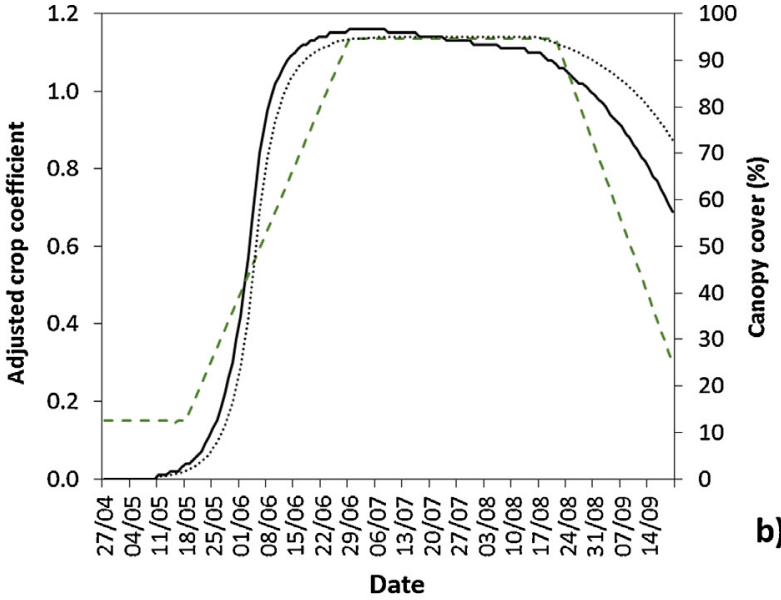

b) c)

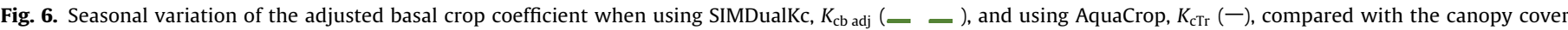
curves (.....) relative to Alpiarça fields: (a) field 2 in 2010, field 1 in 2011 (b), and field 3 in 2012 (c).

Table 8

Sowing and harvesting dates, dry final above ground biomass, yield and harvest index for all maize seasons and fields in Alpiarça.

\begin{tabular}{|c|c|c|c|c|c|}
\hline \multirow[t]{2}{*}{ Field, year } & \multicolumn{2}{|c|}{ Crop season dates } & \multirow[t]{2}{*}{ Harvested dry total above ground biomass $\left(\mathrm{tha}^{-1}\right)$} & \multirow[t]{2}{*}{ Dry total yield $\left(\mathrm{tha}^{-1}\right)$} & \multirow[t]{2}{*}{ Harvest index () } \\
\hline & Sowing & Harvest & & & \\
\hline Field 1, 2010 & $25 / 05$ & $13 / 10$ & $41.86( \pm 8.37)$ & $20.62( \pm 4.14)$ & $0.49( \pm 0.04)$ \\
\hline Field 2, 2010 & $25 / 05$ & $13 / 10$ & $26.27( \pm 5.25)$ & $12.78( \pm 2.56)$ & $0.49( \pm 0.03)$ \\
\hline Field 1, 2011 & $20 / 04$ & $20 / 09$ & $40.02( \pm 5.86)$ & $19.46( \pm 2.97)$ & $0.49( \pm 0.01)$ \\
\hline Field 2, 2012 & $16 / 04$ & $20 / 09$ & $38.70( \pm 7.09)$ & $19.32( \pm 2.63)$ & $0.50( \pm 0.05)$ \\
\hline Field 3, 2012 & $30 / 05$ & $12 / 10$ & $33.62( \pm 7.64)$ & $16.53( \pm 3.72)$ & $0.49( \pm 0.04)$ \\
\hline
\end{tabular}

Standard deviation of observations between brackets

\subsection{Evapotranspiration-yield relations, and biomass and yield predictions}

The observed final harvested biomass, yield and the harvest index for the Alpiarça case study are presented in Table 8; these data was used to test AquaCrop predictions. Higher yields were obtained in field 1 in 2010 and 2011. The lowest yields were obtained in field 2 in 2010 due to poor irrigation management that did not avoid stress during flowering. The variation of yields observed was discussed by Paredes et al. (2014a) aiming at developing more appropriate management scenarios.

The observed average final harvested biomass and yield and the harvest index for all treatments in the Sorraia Valley are presented in Table 9. Results show that higher biomass and yield was attained for the full irrigation treatment $(A)$ followed by the treatment where stress was imposed later in the season (C). Treatment $\mathrm{F}$, where stress was imposed along the crop season, produced the lowest total biomass and yield.
A linear relationship between yield (Tables 8 and 9) and $\mathrm{ET}_{\mathrm{c} \text { adj }}$ and with $T_{a}$ was observed. Fig. 10 presents these relationships using all experimental data relative to both maize hybrids LG18 (FAO 300) and PR33Y74 (FAO 600). The approach adopted herein of using field

Table 9

Dry final above ground biomass, yield and harvest index for all maize treatments (Alves et al., 1991).

\begin{tabular}{llll}
\hline Treatment & $\begin{array}{l}\text { Dry total above } \\
\text { ground biomass } \\
\left(\mathrm{t} \mathrm{ha}^{-1}\right)\end{array}$ & $\begin{array}{l}\text { Dry total yield } \\
\left(\mathrm{tha}^{-1}\right)\end{array}$ & Harvest index () \\
\hline A & $26.57( \pm 3.42)$ & $12.15( \pm 1.20)$ & $0.48( \pm 0.02)$ \\
B & $21.61( \pm 2.19)$ & $10.03( \pm 1.27)$ & $0.46( \pm 0.05)$ \\
C & $25.02( \pm 0.96)$ & $12.23( \pm 0.40)$ & $0.45( \pm 0.08)$ \\
D & $17.59( \pm 0.88)$ & $6.65( \pm 0.26)$ & $0.38( \pm 0.01)$ \\
E & $19.06( \pm 0.27)$ & $7.11( \pm 1.13)$ & $0.38( \pm 0.07)$ \\
F & $14.02( \pm 0.39)$ & $6.66( \pm 0.98)$ & $0.47( \pm 0.06)$ \\
\hline
\end{tabular}

Standard deviation of observations between brackets. 

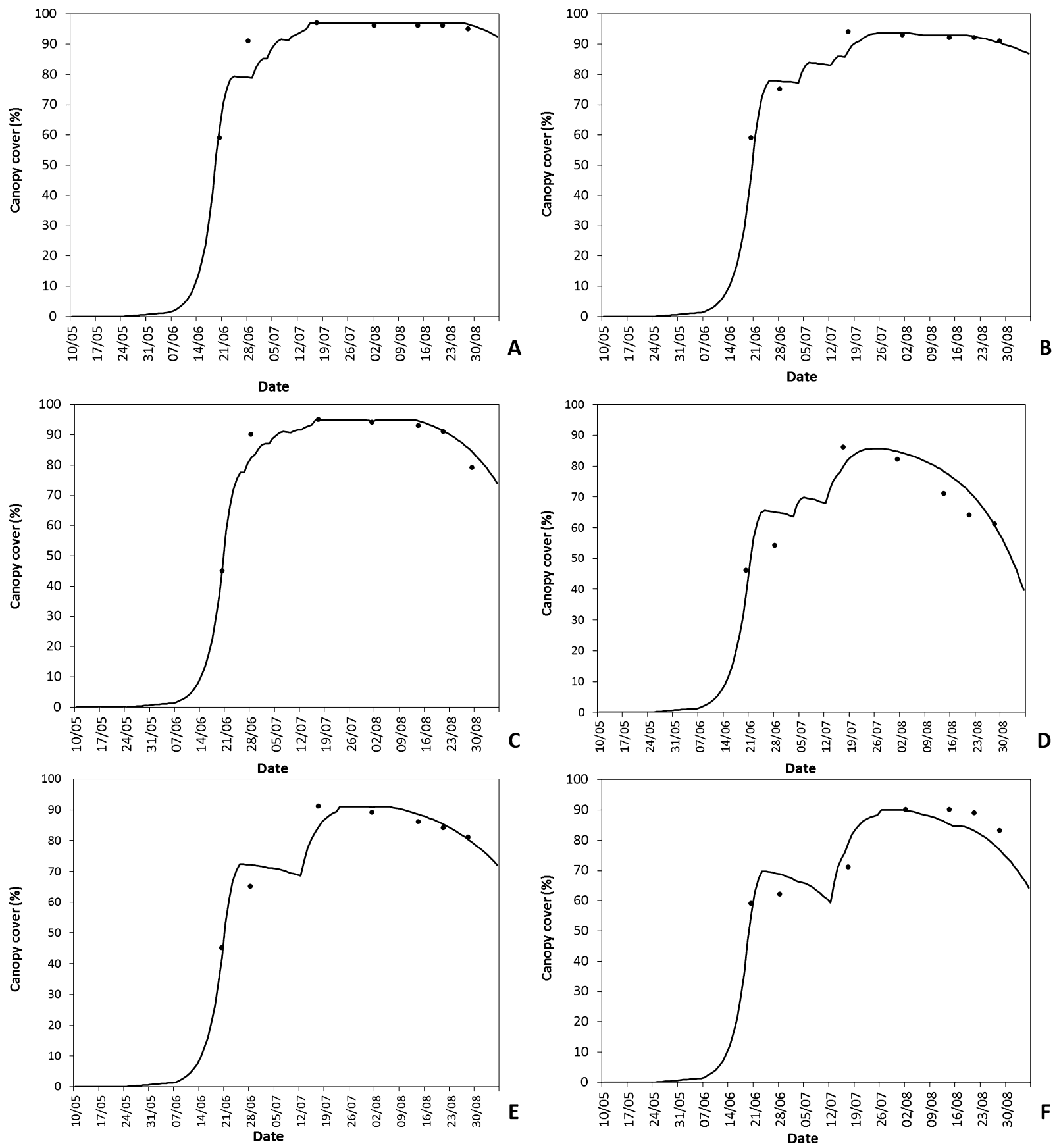

Fig. 7. Selected examples of maize canopy cover (CC) simulated (一) and observed ( $)$ for Sorraia Valley experiments, treatments (A)-(F).

Table 10

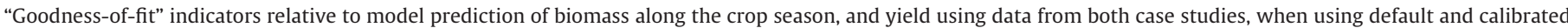
parameters.

\begin{tabular}{|c|c|c|c|c|c|c|}
\hline & & \multicolumn{5}{|c|}{ Goodness of fit indicators } \\
\hline & & $\bar{b}$ & $R^{2}$ & RMSE (tha ${ }^{-1}$ ) & $\mathrm{AAE}\left(\mathrm{t} \mathrm{ha}^{-1}\right)$ & $\mathrm{EF}$ \\
\hline \multirow[t]{2}{*}{ Biomass along crop season } & Default & 0.75 & 0.91 & 7.21 & 5.71 & 0.70 \\
\hline & Calibrated & 0.97 & 0.92 & 3.83 & 2.83 & 0.92 \\
\hline \multirow[t]{2}{*}{ Final dry biomass } & Default & 0.84 & 0.77 & 6.14 & 4.71 & 0.41 \\
\hline & Calibrated & 1.01 & 0.82 & 3.49 & 2.93 & 0.81 \\
\hline \multirow[t]{2}{*}{ Final yield } & Default & 0.84 & 0.82 & 2.51 & 1.77 & 0.63 \\
\hline & Calibrated & 1.05 & 0.87 & 1.73 & 1.45 & 0.82 \\
\hline
\end{tabular}



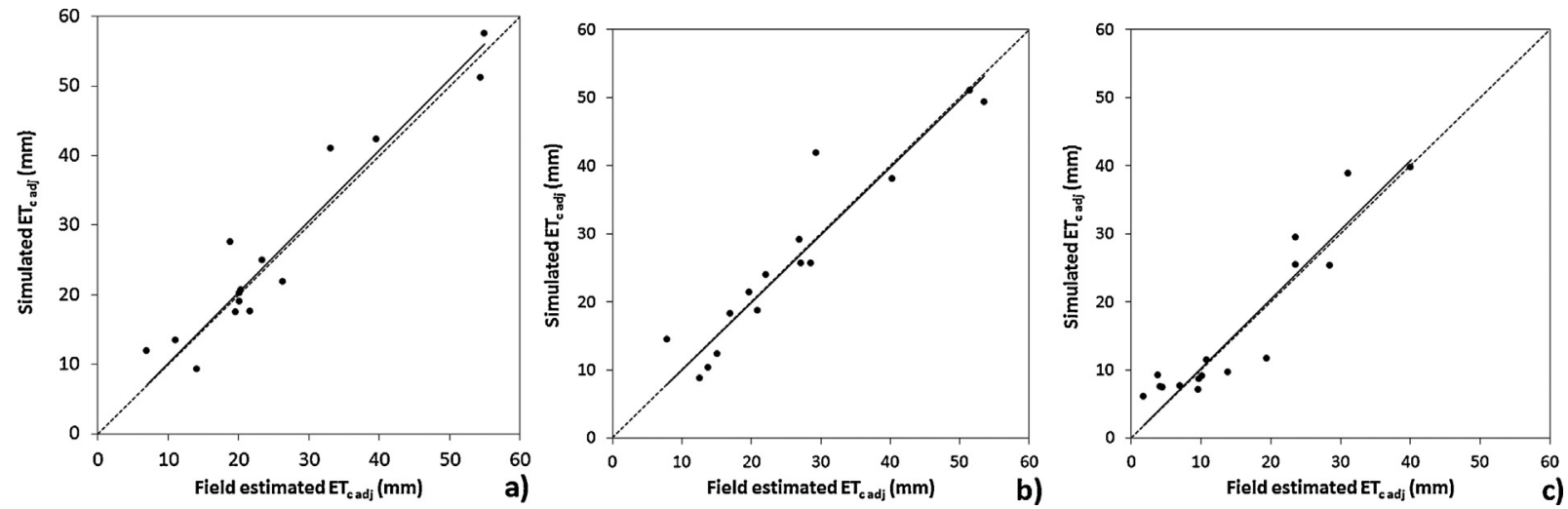

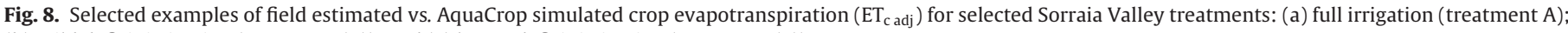
(b) mild deficit irrigation (treatment (B)); and (c) heavy deficit irrigation (treatment (F)).
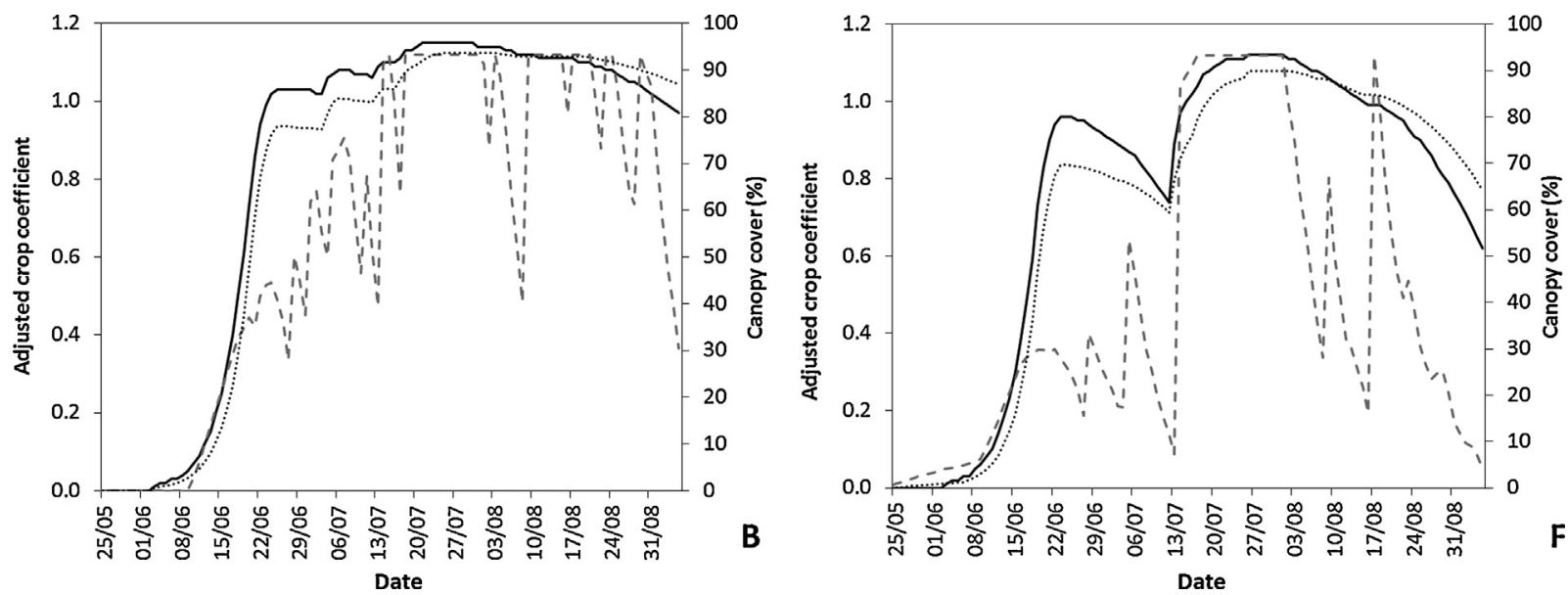

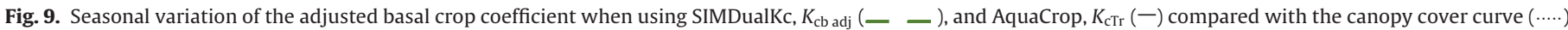
relative to selected examples of $(B)$ and $(F)$ treatments.

observations relative to different hybrids and observation years for yield predictions was also adopted by others, e.g., Retta and Hanks (1980), Liverman et al. (1986) and Paredes et al. (2014a). Results in Fig. 10 indicate a similar behaviour of these hybrids. They also indicate that using the yield- $T_{a}$ relationship is prefer-

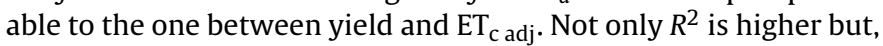

as observed by other authors (Stewart et al., 1977; Payero et al., 2006; Raes et al., 2012; Paredes et al., 2014a), using the yield- $T_{a}$ relationship avoids the variability due to the soil evaporation component, which depends upon crop and irrigation management, and refers only to transpiration that is directly responsible for yield. All data relative to biomass and yield from all the above described case
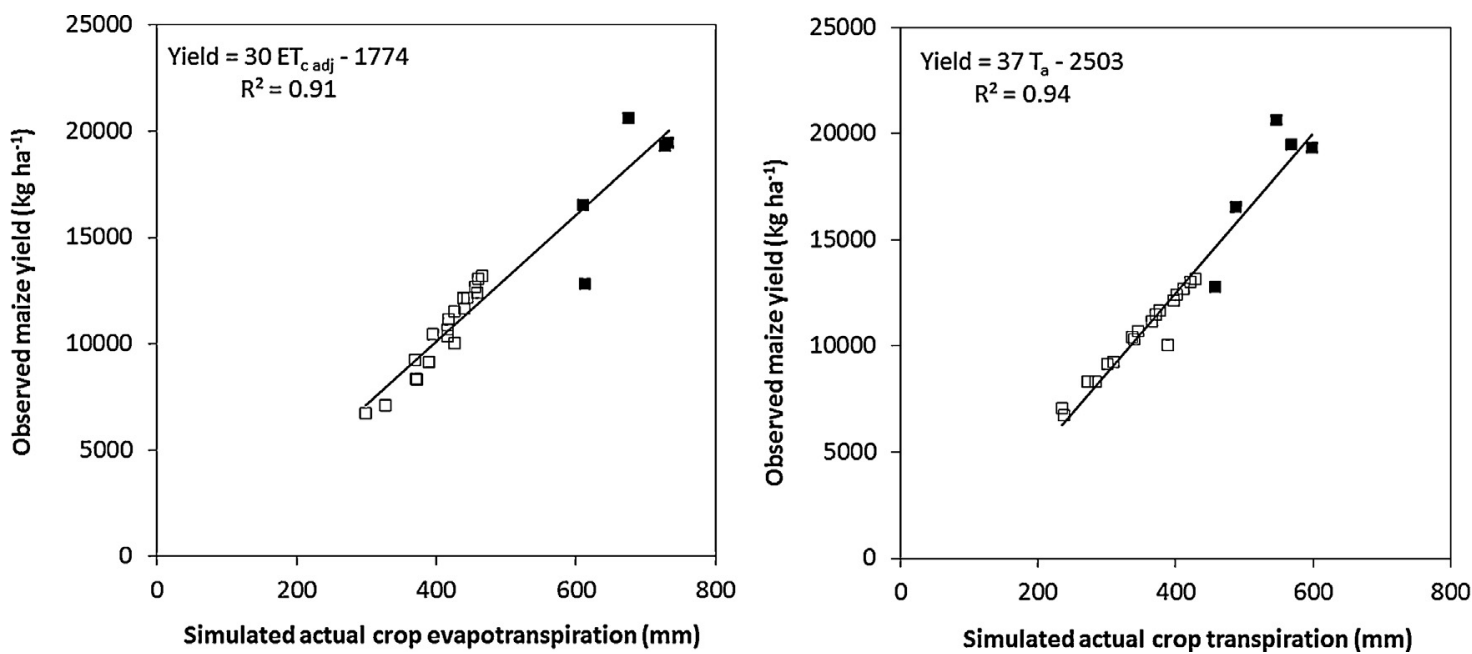

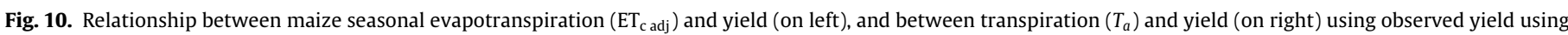
data from all fields of Alpiarça ( $\square$ ) and from all experiments of Sorraia Valley ( $\square$ ). 

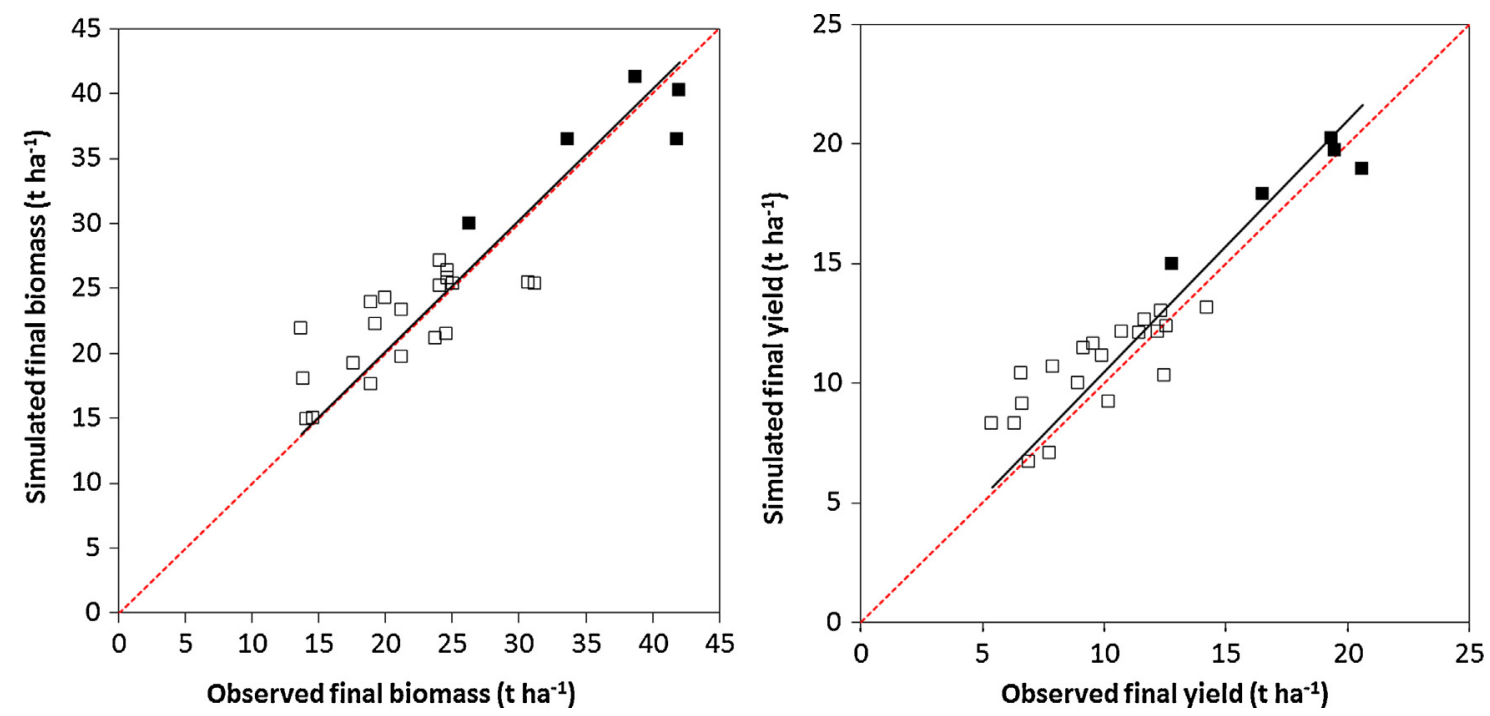

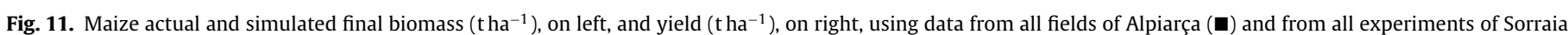
Valley ( $\square)$.

studies (Tables 8 and 9) were used to assess the model accuracy in predicting maize biomass and yield (Fig. 11). When calibrated parameters were used, there was no trend in biomass estimation (Fig. 11a) but just a slight trend for over-estimation of yield (Table 10). The b value is close to 1.0 for biomass predictions and $b=1.05$ for final yield estimation. If default parameters are used then under-estimations occur, with $b \leq 0.84$ and RMSE doubling those observed when calibrated parameters are used. With default parameters, EF is relatively low $(<0.70)$ but is higher when using calibrated parameters $(E F \geq 0.81)$, thus indicating that the residuals variance is much smaller than the observed data variance. Results for biomass and yield predictions therefore evidence the advantage in using appropriately calibrated parameters. The yield over-estimation by AquaCrop is likely related to the above referred insufficiencies in the partition of $\mathrm{ET}_{\mathrm{c} \text { adj }}$ into $E_{S}$ and $T_{a}$, the latter being over-estimated.

Hsiao et al. (2009), Heng et al. (2009) and García-Vila and Fereres (2012) used AquaCrop for predicting maize final dry biomass and reported RMSE values similar to the bulk value given in Table 10. However, the RMSE reported by Heng et al. (2009) for deficit irrigation are larger. Applications of different models led to comparable results, e.g., López-Cedrón et al. (2005) using CERES-Maize, and Ma et al. (2006) with DSAAT-Ceres and RZWQ-CERES. The RMSE results for yield prediction (Table 10) are also comparable with other AquaCrop maize applications, e.g., Heng et al. (2009) and García-Vila and Fereres (2012), as well as with RMSE obtained with different models such as Ma et al. (2006) with the DSAATCeres and RZWQ-CERES models, López-Cedrón et al. (2005), Liu et al. (2011) and DeJonge et al. (2012) with CERES-Maize, Monzon et al. (2012) with CropSyst and CERES-Maize, Cavero et al. (2000) with the EPIC model. In a previous study, using the same case studies data, Paredes et al. (2014a) combined the soil water balance model SIMDualKc with both the global and multi-phasic Stewarts' models and obtained RMSE of 1.80 and $1.21 \mathrm{tha}^{-1}$, respectively, i.e., achieved better results with that simplified approach than with AquaCrop.

\section{Conclusions}

The AquaCrop model was tested using a set of calibrated parameters describing the canopy cover, ET, soil water content, and biomass and yield observed in large farm fields at Alpiarça and in experimental fields at the Sorraia Valley. It was further tested for the same locations using the default parameters provided by Raes et al. (2012). Results showed that a correct calibration of the canopy cover curve parameters highly improved the models' performance because the CC curve is used by the model for daily computations of crop transpiration and soil evaporation. Naturally, if the CC curve adheres to field canopy data it is likely that the resulting transpiration and evaporation estimates are better than those obtained using default parameters.

Results showed an insufficient accuracy of the model in simulating the soil water content dynamics along a crop season particularly if default parameters are used. Therefore, AquaCrop is not suitable for irrigation scheduling purposes. Problems were also identified relative to daily ET calculation and its partition. The adjusted basal crop coefficient is extremely tied to the CC curve, thus less influenced by water stress and leading to over-estimation of plant transpiration. Similarly, soil evaporation is underestimated because it is also made dependent on the CC curve. Nevertheless, the cumulative ET throughout the season could be simulated quite well since the over-estimation of $T_{a}$ is compensated by the underestimation of $E_{s}$. It is therefore advisable to revise the ET partition, using the approaches proposed in FAO56.

Good prediction results were obtained for biomass and crop yield when using properly calibrated parameters. Results showed a slight under-estimation of biomass along the crop season but relatively small errors of estimates were obtained for the final harvested biomass. Differently, the estimations of the final yield have shown a tendency for over-estimation $(b=1.05)$ but with low estimation errors. The referred over-estimations are likely related to the model trend of overestimating transpiration, which is the main driving variable used for yield estimation. When default parameters are used, final biomass and yield estimation have a larger error, nevertheless acceptable for most applications when field data are not available. Summarizing, overall results show adequacy of AquaCrop for estimating biomass and yield.

Results evidence that when using the model for research purposes, thus when high accuracy is desired, it is required to calibrate the canopy cover curve using field data. If the model is to be used for management purposes, it is also necessary to calibrate the model for soil water or ET simulation. Calibration/parameterization is also advisable when accuracy in biomass and yield predictions are desired. However, it is desirable that model developers improve 
the estimations relative to the components of the water balance, mainly aiming at improving the estimation of transpiration, which has major influence on yield estimation.

\section{Acknowledgements}

The support, during the experimental seasons of 2010-12, provided by Engs. Manuel Campilho, Diogo Campilho and Abílio Pereira of Quinta da Lagoalva de Cima are hereby acknowledged. Thanks are due to the colleagues Juliano Martins, Erlán Faria Filho and Diogo Martins for the help during field work. The scholarship SFRH/BD/62339/2009 provided by FCT to P. Paredes is acknowledged. The study was partially funded by the FCT project PTDC/GEO-MET/3476/2012.

\section{References}

Abedinpour, M., Sarangi, A., Rajput, T.B.S., Singh, M., Pathak, H., Ahmad, T., 2012. Performance evaluation of AquaCrop model for maize crop in a semi-arid environment. Agric. Water Manage. 110, 55-66.

Allen, R.G., Pereira, L.S., Raes, D., Smith, M., 1998. Crop Evapotranspiration. Guidelines for Computing Crop Water Requirements. FAO Irrigation and Drainage Paper 56. FAO, Rome, Italy, pp. 300

Allen, R.G., Pereira, L.S., Smith, M., Raes, D., Wright, J.L., 2005. FAO-56 dual crop coefficient method for estimating evaporation from soil and application extensions. J. Irrig. Drain. Eng. 131, 2-13.

Alves, I., Pereira, L.S., 2000. Non-water-stressed baselines for irrigation scheduling with infrared thermometers: a new approach. Irrig. Sci. 19, 101-106.

Alves, I., Fontes, J.C., Pereira, L.S., 1991. Water-yield relations for corn. In: Planning Operation, and Management of Irrigation Systems for Water and Energy Conservation (Proc. Special Tech. Session). Chinese National Committee. ICID, Beijing, pp. 154-161.

Andarzian, B., Bannayan, M., Steduto, P., Mazraeh, H., Barati, M.E., Barati, M.A., Rahnama, A., 2011. Validation and testing of the AquaCrop model under full and deficit irrigated wheat production in Iran. Agric. Water Manage. 100, 1-8.

Araya, A., Habtu, S., Hadgu, K.M., Kebede, A., Dejene, T., 2010. Test of AquaCrop model in simulating biomass and yield of water deficient and irrigated barley (Hordeum vulgare). Agric. Water Manage. 97, 1838-1846.

Bell, J.P., 1976. Neutron probe practice. In: Report No. 19, second ed. Institute of Hydrology, Wallingford, pp. 39.

Çakir, R., 2004. Effect of water stress at different development stages on vegetative and reproductive growth of corn. Field Crops Res. 89, 1-16.

Cameira, M.R., Fernando, R.M., Pereira, L.S., 2003. Monitoring water and $\mathrm{NO}_{3}-\mathrm{N}$ in irrigated maize fields in the Sorraia Watershed, Portugal. Agric. Water Manage. $60,199-216$

Cavero, J., Farré, I., Debaeke, P., Faci, J.M., 2000. Simulation of maize yield under water stress with the EPICphase and CROPWAT models. Agron. J. 92, 679-690.

DeJonge, K.C., Ascough, I.I., Andales, J.C., Hansen, A.A., Garcia, N.C., Arabi, L.A.M, 2012. Improving evapotranspiration simulations in the CERES-Maize model under limited irrigation. Agric. Water Manage. 115, 92-103.

Denmead, O.T., Shaw, R.H., 1960. The effects of soil moisture stress at different stages of growth on the development and yield of corn. Agron. J. 52, 272-274.

Di Paolo, E., Rinaldi, M., 2008. Yield response of corn to irrigation and nitrogen fertilization in a Mediterranean environment. Field Crops Res. 105, 202-210.

Doorenbos, J., Kassam, A.H., 1979. Yield response to water. In: Irrigation and Drainage Paper 33. FAO, Rome, pp. 193.

Doorenbos, J., Pruitt, W.O., 1977. Guidelines for predicting crop water requirements. In: FAO Irrigation and Drainage Paper 24. FAO, Rome, Italy, pp. 156.

FAO, 2006. Guidelines for Soil Description, fourth ed. FAO, Rome, Italy, pp. 97.

Farahani, H.J., Izzi, G., Oweis, T., 2009. Parameterization and evaluation of the AquaCrop model for full and deficit irrigated cotton. Agron. J. 101, 469-476.

Farré, I., Faci, J.-M., 2009. Deficit irrigation in maize for reducing agricultural water use in a Mediterranean environment. Agric. Water Manage. 96, 383-394.

García-Vila, M., Fereres, E., 2012. Combining the simulation crop model AquaCrop with an economic model for the optimization of irrigation management at farm level. Eur. J. Agron. 36, 21-31.

Gao, Y., Duan, A., Sun, J., Li, F., Liu, Z., Liu, H., Liu, Z., 2009. Crop coefficient and wateruse efficiency of winter wheat/spring maize strip intercropping. Field Crops Res. $111(1-2), 65-73$.

Hanks, R.J., Keller, J., Rasmussen, V.P., Wilson, G.D., 1976. Line source sprinkler for continuous variable irrigation-crop production studies. Soil Sci. Soc. Am. J. 44, 886-888 (40, 426-429 Sci. Soc. Am. J.)

Heng, L.K., Hsiao, T., Evett, S., Howell, T., Steduto, P., 2009. Validating the FAO AquaCrop model for irrigated and water deficient field maize. Agron. J. 101 (3), 488-498.

Hodgnett, M.G., 1986. The neutron probe for soil moisture measurements. In: Gensler, W.G. (Ed.), Advanced Agricultural Instrumentation. Design and Use. Martinus Nijhoff Publ., Dordrecht, pp. 148-192.

Hsiao, T.C., Heng, L., Steduto, P., Rojas-Lara, B., Raes, D., Fereres, E., 2009. AquaCrop-the FAO crop model to simulate yield response to water: III. Parameterization and testing for maize. Agron. J. 101, 448-459.
Jackson, R.D., 1982. Canopy temperature and crop water stress. Adv. Irrig. 1, 43-85 Johnson, M.-V.V., Kiniry, J.R., Burson, B.L., 2010. Ceptometer deployment method affects measurement of fraction of intercepted photosynthetically active radiation. Agron. J. 102 (4), 1132-1137.

Karam, F., Breidy, J., Stephan, C., Rouphael, J., 2003. Evapotranspiration yield and water use efficiency of drip irrigated corn in the Bekaa Valley of Lebanon. Agric. Water Manage. 63, 125-137.

Katerji, N., Mastrorilli, M., Cherni, H.E., 2010. Effects of corn deficit irrigation and soil properties on water use efficiency. A 25-year analysis of a Mediterranean environment using the STICS model. Eur. J. Agron. 32, 177-185.

Katerji, N., Campi, P., Mastrorilli, M., 2013. Productivity evapotranspiration, and water use efficiency of corn and tomato crops simulated by AquaCrop under contrasting water stress conditions in the Mediterranean region. Agric. Water Manage. 130, 14-26.

Ko, J., Piccinni, G., Steglich, E., 2009. Using EPIC model to manage irrigated cotton and maize. Agric. Water Manage. 96, 1323-1331.

Liu, H.L., Yang, J.Y., Drury, C.F., Reynolds, W.D., Tan, C.S., Bai, Y.L., He, P., Jin, J., Hoogenboom, G., 2011. Using the DSSAT-CERES-Maize model to simulate crop yield and nitrogen cycling in fields under long-term continuous maize production. Nutr. Cycling Agroecosyst. 89, 313-328.

Liverman, D.M., Terjung, W.H., Hayes, J.T., Mearns, L.O., 1986. Climatic change and grain corn yields in the North American Great plains. Clim. Change 9, 327-347.

López-Cedrón, F.X., Boote, K.J., Ruíz-Nogueira, B., Sal, F., 2005. Testing CERES-Maize versions to estimate maize production in a cool environment. Eur. J. Agron. 23, 89-102.

Ma, L., Hoogenboom, G., Ahuja, L.R., Ascough II, J.C., Saseendran, S.A., 2006. Evaluation of the RZWQM-CERES-Maize hybrid model for maize production. Agric. Syst. 87, 274-295.

Ma, L., Ahuja, L.R., Saseendran, S.A., Malone, R.W., Green, T.R., Nolan, B.T., Bartling, P.N.S., Flerchinger, G.N., Boote, K.J., Hoogenboom, G., 2011. A Protocol for parameterization and calibration of RZWQM2 in field research. In: Ahuja, L.R., Ma, L. (Eds.), Methods of Introducing System Models into Agricultural Research. ASA, CSSA and SSSA, Madsion, WI, pp. 1-64.

Monzon, J.P., Sadras, V.O., Andrade, F.H., 2012. Modelled yield and water use efficiency of maize in response to crop management and Southern Oscillation Index in a soil-climate transect in Argentina. Field Crops Res. 130, 8-18.

Moreno, A., Ramos, T.B., Gonçalves, M.C., Pereira, L.S., 2013. Estimating soil hydraulic properties from limited data to improve irrigation management in agricultural soils of Santiago Island Cape Verde. Irrig. Drain., http://dx.doi.org/ 10.1002/ird.1810.

Moriasi, D.N., Arnold, J.G., Van Liew, M.W., Bingner, R.L., Harmel, R.D., Veith, T.L., 2007. Model evaluation guidelines for systematic quantification of accuracy in watershed simulations. Trans. ASABE 50 (3), 885-900.

Nash, J.E., Sutcliffe, J.V., 1970. River flow forecasting through conceptual models: Part 1-A discussion of principles. J. Hydrol. 10 (3), 282-290.

NeSmith, D.S., Ritchie, J.T., 1992. Short- and long-term responses of corn to preanthesis soil water deficit. Agron. J. 84, 107-113.

Panda, R.K., Behera, S.K., Kashyap, P.S., 2004. Effective management of irrigation water for maize under stressed conditions. Agric. Water Manage. 66, 181-203.

Paredes, P., Rodrigues, G.C., Alves, I., Pereira, L.S., 2014a. Partitioning evapotranspiration, yield prediction and economic returns of maize under various irrigation management strategies. Agric. Water Manage 135, 27-39 (Corrigendum Agric. Water Manage., 141, 84).

Paredes, P., Rodrigues, G.C., Torres, M.O., Pereira, L.S., 2014b. Evapotranspiration partitioning and yield prediction of peas (Pisum sativum L. cV. Azarro) in a Mediterranean environment. Field Crops Res. (submitted).

Paredes, P., Rodrigues, G.C., Cameira, M.R., Torres, M.O., Neves, M., Pereira, L.S., 2014c. Modeling water use, partition of evapotranspiration and predicting yields of barley under supplemental irrigation in a Mediterranean environment. Irrig. Sci. (submitted).

Payero, J.O., Melvin, S.R., Irmak, S., Tarkalson, D., 2006. Yield response of corn to deficit irrigation in a semiarid climate. Agric. Water Manage. 84, 101-112.

Piccinni, G., Ko, J., Marek, T., Howell, T., 2009. Determination of growth-stagespecific crop coefficients $\left(K_{c}\right)$ of maize and sorghum. Agric. Water Manage. 96, 1698-1704.

Popova, Z., Pereira, L.S., 2011. Modelling for maize irrigation scheduling using long term experimental data from Plovdiv region, Bulgaria. Agric. Water Manage. 98, 675-683.

Raes, D., Steduto, P., Hsiao, T.C., Fereres, E., 2012. Crop Water Productivity. Calculation Procedures and Calibration Guidance. AquaCrop version 4.0. FAO Land and Water Development Division, Rome.

Ramos, T.B., Šimünek, J., Gonçalves, M.C., Martins, J.C., Prazeres, A., Castanheira, N.L., Pereira, L.S., 2011. Field evaluation of a multicomponent solute transport model in soils irrigated with saline waters. J. Hydrol. 407, 129-144.

Ramos, T.B., Gonçalves, M.C., Martins, J.C., Pereira, L.S., 2014. Comparação de diferentes funções de pedotransferência para estimar as propriedades hidráulicas em Portugal. In: Gonçalves, M.C., Ramos, T.B., Martins, J.C. (Eds.), Proceedings Encontro Anual de Ciência do Solo. Instituto Nacional de Investigação Agrária e Veterinária, Oeiras, Portugal, pp. 29-34 (in Portuguese).

Rawls, W.J., Gimenez, D., Grossman, R., 1998. Use of soil texture, bulk density, and slope of the water retention curve to predict saturated hydraulic conductivity. Trans. ASAE 41 (4), 983-988.

Retta, A., Hanks, R.J., 1980. Corn and alfalfa production as influenced by limited irrigation. Irrig. Sci. 1, 135-147.

Rodrigues, G.C., Paredes, P., Gonçalves, J.M., Alves, I., Pereira, L.S., 2013. Comparing sprinkler and drip irrigation systems for full and deficit irrigated maize using 
multicriteria analysis and simulation modeling: ranking for water saving vs. farm economic returns. Agric. Water Manage. 126, 85-96.

Rosa, R.D., Paredes, P., Rodrigues, G.C., Fernando, R.M., Alves, I., Pereira, L.S., Allen, R.G., 2012. Implementing the dual crop coefficient approach in interactive software: 2. Model testing. Agric. Water Manage. 103, 62-77.

Sentek, 2001. Calibration of Sentek Pty Ltd Soil Moisture Sensors. Australia Sentek Pty Ltd., Stepney, South Australia, pp. 60.

Steduto, P., Hsiao, T.C., Fereres, E., Raes, D., 2012. Crop Yield Response to Water. FAO Irrigation and Drainage Paper 66. FAO, Rome, Italy, pp. 500.

Stewart, J.I., Hagan, R.M., Pruitt, W.O., Danielson, R.E., Franklin, W.T., Hanks, R.J., Riley, J.P., Jackson, E.B., 1977. Optimizing crop production through control of water and salinity levels in the soil. In: Reports Paper 67. Utah Water Research Laboratory, USA, pp. 191.

Stöckle, C.O., Donatelli, M., Nelson, R., 2003. Crop Syst a cropping systems simulation model. Eur. J. Agron. 18, 289-307.

Stone, P.J., Wilson, D.R., Reid, J.B., Gillespie, R.N., 2001a. Water deficit effects on sweet corn. I. Water use radiation use efficiency, growth and yield. Aust. J. Agric. Res. $52,103-113$.
Stone, P.J., Wilson, D.R., Jamieson, P.D., Gillespie, R.N., 2001b. Water deficit effects on sweet corn. II. Canopy development. Aust. J. Agric. Res. 52, 115-126.

Traore, S.B., Carlson, R.E., Pilcher, C.D., Rice, M.E., 2000. Bt and Non-Bt maize growth and development as affected by temperature and drought stress. Agron. J. 92, 1027-1035.

Weerathaworn, P., Thiraporn, R., Soldati, A., Stamp, P., 1992. Yield and agronomic characters of tropical maize (Zea mays L) cultivars under different irrigation regimes. J. Agron. Crop Sci. 168, 326-336.

Westgate, M.E., Grant, D.L.T., 1989. Water deficits and reproduction in maize Response of the reproductive tissue to water deficits at anthesis and mid-grain fill. Plant Physiol. 91, 862-867.

Zeleke, K.T., Luckett, D., Cowley, R., 2011. Calibration and testing of the FAO AquaCrop model for canola. Agron. J. 103, 1610-1618.

Zhang, B., Liu, Y., Xu, D., Zhao, N., Lei, B., Rosa, R.D., Paredes, P., Paço, T.A., Pereira, L.S., 2013. The dual crop coefficient approach to estimate and partitioning evapotranspiration of the winter wheat-summer maize crop sequence in North China Plain. Irrig. Sci. 31, 1303-1316. 